\title{
Mineralogía y geocronología de rutilo-(Nb,Ta) relacionado a casiterita y columbita-tantalita provenientes de rocas Mesoproterozoicas del Cratón Amazónico cerca de Cachicamo, Colombia
}

\author{
Jose Alejandro Franco ${ }^{1,2^{*}} \mathbb{D}$; Thomas Cramer $^{1,2} \mathbb{D}$; Amed Bonilla ${ }^{2} \mathbb{D}$; Antonio Jose Castañeda ${ }^{2,3} \mathbb{D}$; \\ Marc Poujol $^{2,4}$; Zeze Amaya²
}

Forma de citar: Franco, J.A.; Cramer, T.; Bonilla, A.; Castañeda, A.J.; Poujol, M.; Amaya, Z. (2021). Mineralogía y geocronología de rutilo-(Nb,Ta) relacionado a casiterita y columbita-tantalita provenientes de rocas Mesoproterozoicas del Cratón Amazónico cerca de Cachicamo, Colombia. Boletín de Geología, 43(1), 99-126. https://doi.org/10.18273/revbol.v43n1-2021005

\section{Resumen}

Para resolver la pregunta si megacristales de rutilo-(Nb,Ta) en la Comunidad Indígena de Cachicamo (NE-Vichada) provienen de rocas del Granito Rapakivi de Parguaza se extrajeron rutilos de una coraza ferruginosa superficial o duricrust compuesta por (hematita, limonita, \pm magnetita, ilmenita, circón, fragmentos de roca), desarrollada sobre un perfil laterítico del basamento granítico, que fueron analizados junto a suelos y concentrados. Mediciones simultáneas de densidad y FRXp de $>250$ rutilos revelaron variaciones fuertes desde rutilos livianos $\left(\sim 3,4 \mathrm{~g} / \mathrm{cm}^{3}\right)$, de casi puro $\mathrm{TiO}_{2}$, hasta rutilos-(Nb,Ta) de 5,9 g/ $\mathrm{cm}^{3}$ enriquecidos en $\mathrm{Nb}, \mathrm{Ta}, \mathrm{Fe}, \mathrm{Mn}, \mathrm{Sn}, \mathrm{V}$ y W. Metalografía, MEB-EDX, FRX y DRX revelaron inclusiones de hasta $0,2 \mathrm{~mm}$ compuestas de $\sim 17 \%$ columbita-(Fe) y $4 \%$ casiterita en una matriz de $\sim 78 \%$ rutilo-(Nb,Ta). Valores EPMA $\left(72 \% \mathrm{TiO}_{2}, 11 \% \mathrm{Nb}_{2} \mathrm{O}_{5}, 9 \% \mathrm{Ta}_{2} \mathrm{O}_{5}, 6 \% \mathrm{Fe}_{2} \mathrm{O}_{3}, 1,5 \% \mathrm{SnO}_{2}\right.$ ) confirman junto con bajos contenidos de W y Mn una afinidad pegmatítica - pneumatolítica. Mediciones ICP-MS indicaron suficiente U para probar dataciones en la Universidad Rennes 1, donde, usando estándares R10 y R19, diez rutilos-(Nb,Ta), arrojaron edades de cristalización U/Pb concordantes de 1512 \pm 12 Ma. Estas edades coinciden con observaciones de campo, según las cuales los rutilos-(Nb,Ta) de Cachicamo cristalizaron en el Granito de Parguaza hace 1500-1550 Ma en Venezuela, donde depósitos secundarios contienen mineralizaciones comparables (sub-?) económicas de casiterita, rutilo-(Nb,Ta), columbita-tantalita y monacita. El análisis de minerales pesados (circón, ilmenita, magnetita) muestra que los rutilos-(Nb,Ta) se limitan al duricrust del horizonte A, donde circones detríticos de 1525 Ma son coetáneos al Batolito de Parguaza en Venezuela (1500-1550 Ma), mientras los circones del horizonte C (regolito) con 1415 Ma tienen edades similares al Granito Rapakivi Parguaza local (1340-1402 Ma) en estas partes distales del Batolito en Colombia. Así, los rutilos(Nb,Ta) de Cachicamo no se pueden haber formado in-situ sino que experimentaron un transporte post-exhumación por decenas de kilómetros atravesando lo que actualmente es el valle del río Orinoco.

Palabras clave: Mineralogía; FRXp; Geocronología; Rutilo-(Nb,Ta); Cratón Amazónico; Colombia.

\section{Mineralogy and $\mathrm{U} / \mathrm{Pb}$ ages of rutile-(Nb,Ta) related to cassiterite, and columbite from Mesoproterozoic rocks of the Amazonian Craton near Cachicamo, Colombia}

\begin{abstract}
In order to clarify if rutile-(Nb,Ta) mega-crystals in the Indigenous Cachicamo community (NE-Vichada-department, Colombia) are derived from rocks of the Parguaza Rapakivi Granite suite, samples were extracted from a ferruginous duricrust layer (composed of hematite, goethite, limonite, \pm magnetite, ilmenite, zircon, and rock fragments) of a lateritic profile over granitoid basement rocks and analyzed together with soils and concentrates. Density and pXRF measurements of $>250$ rutiles revealed a strong variation from lowdensity $\left(\sim 3.4 \mathrm{~g} / \mathrm{cm}^{3}\right.$ ), nearly-pure $\mathrm{TiO}_{2}$-rutiles, to rutile-(Nb,Ta) crystals (up-to $5.9 \mathrm{~g} / \mathrm{cm}^{3}$ ) enriched in $\mathrm{Nb}, \mathrm{Ta}, \mathrm{Fe}, \mathrm{Mn}, \mathrm{Sn}, \mathrm{V}$ and $\mathrm{W}$. Metallography, SEM-EDX, XRF and XRD exhibited up-to $0.2 \mathrm{~mm}$ - inclusions of $\sim 17 \%$ columbite-(Fe) and $4 \%$ cassiterite in a $~ 78 \%$ rutile-(Nb,Ta) matrix, where EPMA values of $\sim 72 \% \mathrm{TiO}_{2}, 11 \% \mathrm{Nb}_{2} \mathrm{O}_{5}, 9 \% \mathrm{Ta}_{2} \mathrm{O}_{5}, 6 \% \mathrm{Fe}_{2} \mathrm{O}_{3}$ and $1.5 \% \mathrm{SnO}_{2}$ confirm, together with low $\mathrm{W}$ and $\mathrm{Mn}$, pegmatitic-pneumatolytic conditions. ICP-MS measurements yielded enough U for encouraging LA-ICP-MS dating in the University of Rennes 1, where, using rutile standards R10 and R19, in ten rutile-(Nb,Ta) crystals, concordant U/Pb-ages of $1512 \pm 12$ My were determined. These ages confirm the former assumption based on field observation that the Cachicamo rutiles-( $\mathrm{Nb}, \mathrm{Ta})$ originally crystalized within the 1500-1550 My-old Parguaza Granite in Venezuela, where secondary deposits contain similar (sub?) economic cassiterite, rutile-(Nb,Ta), columbite-tantalite and monazite. Additionally, the analysis of different horizons containing zircon, ilmenite and magnetite, showed that rutiles-(Nb,Ta) are restricted to the duricrust horizon. Detrital zircons from the A-horizon (duricrust) revealed a similar age span of 1525 My, which is coeval with the Parguaza Batholith reported in Venezuela, whereas ages of 1415 My of zircons from the C-horizon (regolith) coincide with the local Parguaza Rapakivi Granite ages (1340-1402 My). Hence, this study supports a nonlocal source for the Cachicamo rutile-(Nb,Ta) crystals, which probably had experienced a post-exhumation transport westward over several tens of kilometres through a zone which nowadays is deepened by the Orinoco-river valley.
\end{abstract}

Keywords: Mineralogy; pXRF; Geochronology; Rutile-(Nb,Ta); Amazonian Craton; Colombia.

${ }^{1}$ Universidad Nacional de Colombia, Bogotá, Colombia. (*) jafrancov@unal.edu.co; thcramer@unal.edu.co

${ }^{2}$ Grupo de Estudios en Geología Económica y Mineralogía Aplicada, Universidad Nacional de Colombia, Bogotá, Colombia. abonillape@unal.edu.co; ajcastanedag@unal.edu.co; marc.poujol@univ-rennes1.fr; zamayap@unal.edu.co

${ }^{3}$ Julius Maximilians Universität Würzburg, Wurzburgo, Alemania.

${ }^{4}$ Université Rennes 1, CNRS, Géosciences Rennes-UMR 6118, F-35000 Rennes, Francia. 


\section{Introducción}

La explotación artesanal de minerales con $\mathrm{Ti}, \mathrm{Ta}, \mathrm{Nb}$, $\mathrm{Sn}, \mathrm{Fe}$ y $\mathrm{W}$ en depósitos sedimentarios con métodos simples como barequeo durante las últimas décadas en los departamentos de Vichada y Guainía requiere para su transformación en una minería sostenible como paso indispensable un mayor conocimiento acerca de la naturaleza de los mismos, su significado geológico, los procesos involucrados desde su formación primaria $\mathrm{y}$ enriquecimiento secundario, las asociaciones minerales que lo acompañan, su distribución, volumen, valor económico real y los riesgos y oportunidades de su extracción y beneficio.

Hasta el momento hemos identificado en el Departamento del Vichada tres áreas con mineralizaciones en depósitos secundarios de Ti, Nb y Ta en los Cerros de Cachicamo, de Sn en los cerros de Casuarito - San Roque y parcialmente de $\mathrm{Nb}, \mathrm{Ta}$, Mn, y W, en Cerro Hormiga - Río Vichada. También cerca de la frontera colombo-venezolana minerales de la serie columbita-tantalita (Figura 1) $[(\mathrm{Fe}, \mathrm{Mn})$ $\mathrm{Nb}_{2} \mathrm{O}_{6}-(\mathrm{Fe}, \mathrm{Mn}) \mathrm{Ta}_{2} \mathrm{O}_{6}$ ], estruveritas, casiteritas ricas en Ta, rutilos-(Ta) entre otros, relacionados al Granito de Parguaza, han formado acumulaciones considerables de $\mathrm{Sn}, \mathrm{W}$, Ta y Nb. Otras ocurrencias de tantalita-columbita y casiterita asociadas al Granito de Parguaza se encuentran en cercanías a Puerto Carreño (Cristancho, 1989; Rodríguez, 1996).

El notable potencial mineral de este segmento del Cratón Amazónico ha sido objeto de numerosos estudios (ej. Priem et al., 1982; Santos et al., 2000; Tassinari y Macambira, 1999), los cuales han evidenciado los constituyentes petrogenéticos principales de las unidades cristalinas, y en algunos casos su edad, sin embargo, aún con enormes vacíos en la cronología de las mineralizaciones de interés económico y las consideraciones específicas de su origen.

En el área de estudio en cercanías del municipio de Cachicamo, junto al río Orinoco (Figura 1), el hallazgo de mineralizaciones de rutilo-(Nb,Ta) y casiteritas exclusivamente en corazas ferruginosas evidencia que estos minerales no provienen de la meteorización insitu de una fuente primaria, sino que han sido producto de un ciclo sedimentario de segundo orden en el cual el retrabajamiento de antiguas corazas ferruginosas, mezcladas con sedimentos provenientes del granito y litologías relacionadas fueron incorporadas dentro de una coraza ferruginosa más reciente (Franco, 2011).
Adicionalmente, se ha documentado que el origen primario de estas mineralizaciones de Nb, Ta y Sn típicamente se relaciona a fases post-magmáticas como pegmatitas enriquecidas en elementos raros como (ej. $\mathrm{Nb}, \mathrm{Ta}, \mathrm{U}, \mathrm{Li}$ ) y venas de cuarzo relacionadas a rocas de composición sienítica a monzogranítica con textura rapakivi emplazadas en ambientes anorogénicos como el Granito de Parguaza (ej. Sial et al., 2011; Bonilla-Pérez et al., 2013). Por lo tanto, el hallazgo de corazas ferruginosas ricas en minerales de $\mathrm{Nb}$, Ta alrededor de Cachicamo cerca del río Orinoco, presenta una contradicción ya que manifestaciones pegmatíticas enriquecidas en estos minerales no han sido documentadas en esta localidad en las rocas graníticas aflorantes.

Para resolver estas inquietudes es necesario trazar el origen de estas fases minerales ricas en $\mathrm{Nb}$ y $\mathrm{Ta}$, mediante análisis de proveniencia. Los minerales comúnmente utilizados para este propósito son los que acumulan suficiente $\mathrm{U}$, Th o $\mathrm{K}$, especialmente el circón, apatito, granate, piroxeno, hornblenda, monacita, turmalina, epidota, rutilo y en general las asociaciones de minerales pesados y resistentes a la meteorización y abrasión. En los últimos años rutilos han demostrado ser versátiles geocronómetros y termómetros (Meinhold, 2010) y su uso en estudios de proveniencia se ha vuelto una práctica frecuente, dada su resistencia a la abrasión mecánica y química, incluyendo termometría de $\mathrm{Zr}$-en rutilo (Watson et al., 2006).

El rutilo permite también calcular directamente edades de cristalización debido a su temperatura de cierre en el sistema $\mathrm{U} / \mathrm{Pb}$ entre 500 y $400^{\circ} \mathrm{C}$ (ej. Carlson, 2011).

En esta contribución nos enfocamos en la caracterización geoquímica e isotópica de rutilo enriquecido en $\mathrm{Nb}$ y/o $\mathrm{Ta}$, que junto con columbitatantalita y casiterita han sido utilizados en menor medida para datar eventos mineralizantes o estudios de proveniencia (Melcher et al. 2015, 2017; Dill et al., 2006). La combinación de datación $\mathrm{U} / \mathrm{Pb}$ utilizando el par rutilo - circón ha permitido reconstruir historias termales complejas y configurar estudios de mineralizaciones y proveniencia (ej. Košler y Sylvester, 2003; Howard et al., 2009).

Presentamos 19 nuevas edades, LA-ICP-MS U/ $\mathrm{Pb}$ obtenidas de 12 cristales de rutilos-(Nb,Ta) con inclusiones de columbita y casiterita y circones detríticos encontrados en corazas ferruginosas en Cachicamo, Vichada, acopladas a geoquímica y 
nuestras detalladas observaciones de campo, los cuales en síntesis revelan: 1) la edad del evento mineralizante y 2) la posible roca fuente de la cual provienen. Nuestros resultados permiten concluir que las mineralizaciones ricas en $\mathrm{Nb}$ y Ta fueron originadas en una localidad distante de su punto actual de acumulación.
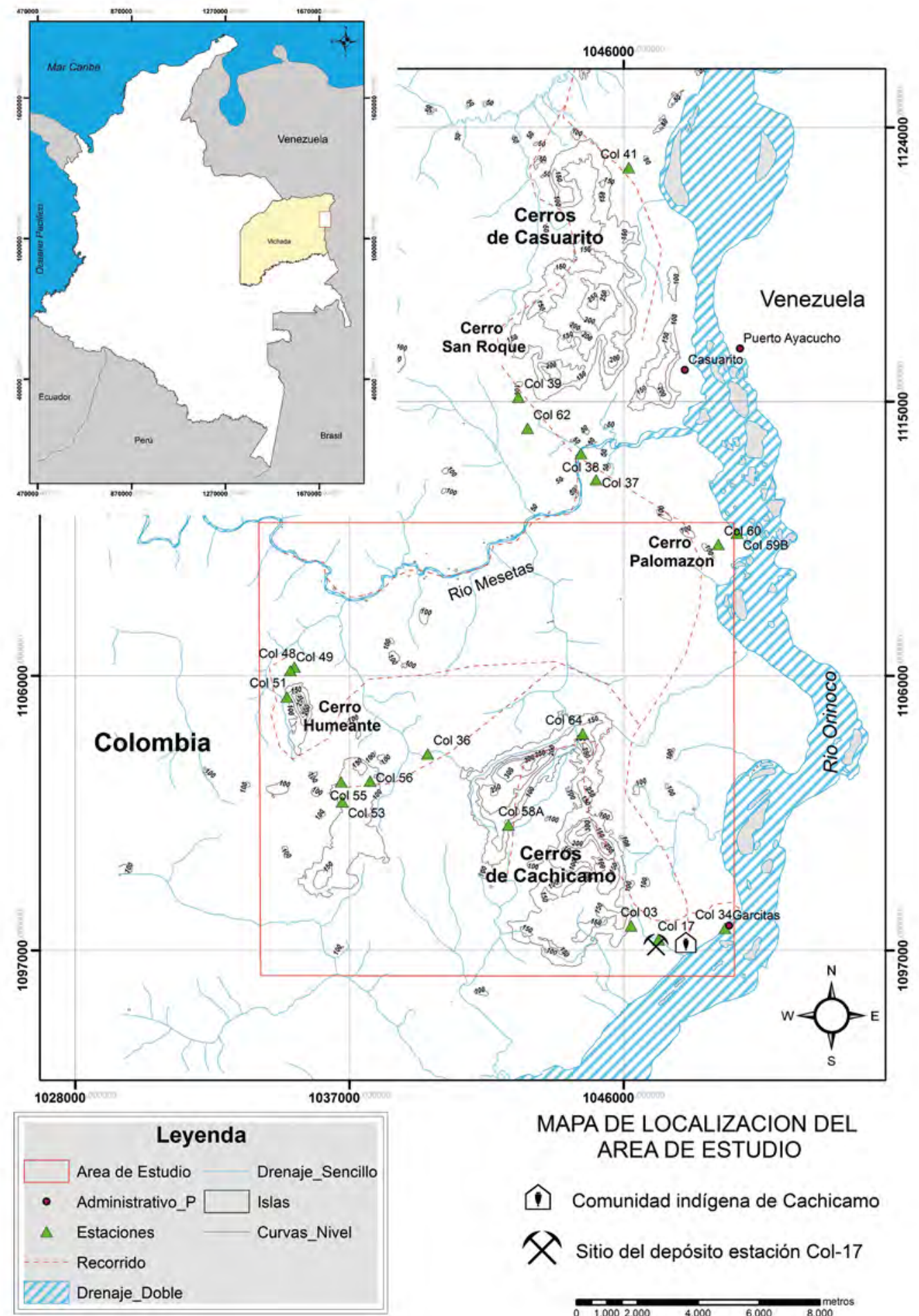


\section{Marco Teórico}

\section{Geología regional y procesos mineralizantes}

Las rocas del Proterozoico en el oriente de Colombia están representadas por el Complejo Mitú (López et al., 2007) con edades entre 1800 y 1500 Ma pertenecientes a la Provincia Rio Negro-Juruena del Cratón Amazónico (Priem et al., 1982; Cordani et al., 2016; Bonilla et al., 2019). Sin embargo, en el área de estudio el basamento cristalino está conformado por rocas más jóvenes relacionadas a la intrusión del Granito de Parguaza durante el Mesoproterozoico entre 1550 y 1400 Ma (Bonilla-Pérez et al., 2013).

A nivel global se han registrado varios eventos magmáticos anorogénicos de gran importancia durante el Mesoproterozoico, entre los cuales en Sur América se encuentra el Granito de Parguaza, compuesto en su mayoría por monzo a sienogranitos y granitos de feldespato alcalino con una textura rapakivi bien desarrollada, que fueron emplazados dentro de la Provincia Rio Negro-Juruena con edades entre 1,801,55 Ga (Tassinari y Macambira, 1999) y la Provincia Ventuari-Tapajós con edades entre 1,90-1,80 Ga. En Venezuela, el Granito de Parguaza presenta edades U/Pb en circones entre 1550 y $1500 \mathrm{Ma}$ (Gaudette et al., 1978; Priem et al., 1982), mientras que en el Departamento del Vichada en Colombia las edades U/Pb en circones entre 1402 y 1398 Ma son notoriamente más jóvenes (Bonilla-Pérez et al., 2013), y edades Ar/Ar entre 1380 y 1300 Ma son interpretadas como de enfriamiento postmagmático de minerales con $\mathrm{K}$ como filosilicatos y anfíboles, menores rangos de temperatura podrían indicar también metamorfismo (Servicio Geológico Colombiano, 2013). Otros granitos de textura rapakivi son descritos al norte del Departamento de Guainía (Franco, 2011; Cramer et al., 2011), con edades LAICP-MS U/Pb en circones de 1340 Ma (Bonilla et al., 2016), siendo más cercanos a la edad de 1400 Ma para el Granito de Parguaza y reflejan una serie de episodios de magmatismo anorogénico durante el Proterozoico que se rejuvenecen en dirección occidental, también descritos en el SW del Cratón Amazónico (Bettencourt et al., 1999).

Para los granitos rapakivi en Colombia no han sido reportadas edades mayores a 1400 Ma. Una razón puede ser la falta de afloramientos, o simplemente que el rifting continental que favorece la formación de granitos rapakivi requiere una corteza continental con un cierto grado de consolidación (Best, 2003) que en las partes acrecionadas hacia el occidente no se habían dado en el borde externo del escudo
Guayanés. Adicionalmente se ha planteado que entre 1500 y 1400 Ma a nivel global ocurrió una disminución de magmatismo. Esto se evidencia por la ausencia de edades $\mathrm{U} / \mathrm{Pb}$ de granitos rapakivi así como mineralizaciones de $\mathrm{Ta}$, Nb, Sn en pegmatitas y granitos de metales raros para este intervalo en el Cratón Amazónico (Dall’Agnol et al., 1999) y en África (Melcher et al., 2015). Este periodo de silencio magmático puede asociarse a una fuerte disminución de procesos de formación de corteza continental y emplazamiento de pegmatitas entre 1400 a 1100 Ma (Tkachev, 2011).

El Vichada (Figura 1) presenta un paisaje con alturas entre 75 y $300 \mathrm{msnm}$, que se ha formado por procesos de meteorización química y física en un clima tropical húmedo que causaron denudación doble (Büdel, 1981) en los últimos millones de años y han formado depósitos sedimentarios que cubren gran parte del basamento cristalino del cual hoy aflora el Granito de Parguaza (Mendoza, 2012). En la zona de estudio sobresalen de la extensa sabana cenozoica los Cerros de Cachicamo como expresiones morfológicas del Granito de Parguaza con textura rapakivi y edades U/Pb LA-ICPMS en circones entre 1390 a 1402 Ma (Bonilla-Pérez et al., 2013) notablemente más jóvenes que granitos de textura rapakivi documentados en Venezuela que registran edades de ca. 1550 Ma (Gaudette et al., 1978) producto de magmatismo anorogénico; asociado al Granito de Parguaza en Venezuela se presentan depósitos aluviales enriquecidos en $\mathrm{Sn}, \mathrm{Ta}, \mathrm{Nb}, \mathrm{Zr}$ y Ti (Sidder y Mendoza, 1995).

\section{Minerales de Nb y Ta en Colombia}

Los primeros reportes sobre minerales de tantalio en Colombia (INGEOMINAS-USGS, 1986) mencionan además elementos de tierras raras en fosfatos en el departamento del Vichada, así como contenidos elevados de $\mathrm{Nb}$ (70 ppm) en sedimentos y columbitastantalitas de una vena pegmatítica en cercanías a Puerto Carreño (Buenaventura y Rosas 1988). Mineralizaciones de Fe, Al, Sn, Au, Ag, elementos de tierras raras y minerales como amazonita y amatista, casiterita y tantalita posiblemente asociadas a diques emplazados en las rocas del Granito de Parguaza también han sido descritos (Cristancho, 1989).

Posteriormente Navas (1991) pronostica para el área estudiada entre Puerto Carreño y Casuarito un alto potencial minero, ya que en el Granito de Parguaza en Venezuela cerca de la frontera con Colombia presenta depósitos de hierro, bauxitas, tantalio, niobio y tierras 
raras. De acuerdo con el U.S. Geological Survey y la Corporación Venezolana de Guayana (Brooks y Gray, 1993), el dominio permisible para los depósitos de placer de minerales de $\mathrm{Sn}, \mathrm{Nb}$ y Ta incluye drenajes que disectan al Granito del Parguaza y hacen parte de la Cuenca del río Orinoco; drenajes de otras áreas podrían ser considerados permisibles para depósitos tipo greisen de Sn. López-Africano (1998) reporta mineralizaciones de $\mathrm{Ta}$ y $\mathrm{Nb}$ en la cuenca media $\mathrm{y}$ alta de los ríos Guainía e Inírida.

INGEOMINAS (2006) profundiza la exploración del oriente colombiano con proyectos, como el Mapa Geoquímico de Colombia y el Proyecto del Potencial de Recursos Minerales en el Oriente Colombiano. Este último evalúa ocurrencias de tantalio y niobio en los departamentos del Vichada, Guainía y Vaupés. Según INGEOMINAS (2006) las zonas de falla a lo largo de las rocas del Granito de Parguaza pueden contener diques pegmatíticos ricos en minerales de Ta, Nb y Sn y se reportan minerales de Ta y $\mathrm{Nb}$ en el este del Vichada. El Granito de Parguaza generalmente está relacionado con diques graníticos, pegmatíticos, enclaves y xenolitos. Otros estudios realizados por INGEOMINAS (2009) indican la presencia de cuerpos graníticos con textura rapakivi en los sectores Bandera, Bita, Ventana, Mis Amores, La Hormiga, Murciélago, Guarípa y Laguna El Pañuelo. Como mineral característico se presenta la magnetita, especialmente en el área de Guarípa y La Hormiga. Los diques graníticos se observaron en el casco urbano de Casuarito y los cerros de Casuarito, Bachaco, Bita, Ángela, San Roque y La Hormiga.

Diques pegmatíticos compuestos por cuarzo y feldespatos se observaron en los cerros Bita, La Hormiga, Bandera, Santa Helena, Casuarito, San Roque, Guarípa y en el municipio de Puerto Carreño, cortando los cuerpos graníticos presentes y los enclaves, además según INGEOMINAS (2009) algunos autores han observado columbita -tantalita como componente de dichos cuerpos.

También otros estudios en los departamentos del Guainía, Vichada, Vaupés y países vecinos de Colombia (por ejemplo, Buenaventura y Rosas 1988; Brooks y Gray, 1993; López-Africano, 1998; Galvis, 2001; Carrasco y Peña, 2006) mencionan minerales o anomalías geoquímicas de $\mathrm{Nb}-\mathrm{Ta}, \mathrm{Sn}, \mathrm{Ti}, \mathrm{W}, \mathrm{Fe}$ y Mn. Hacia el sur de Colombia, en el Departamento de Guainía, López et al. (2010) reportan anomalías de tantalio y niobio y mineralizaciones de coltán.

\section{Metodología}

En el trabajo de campo se realizó la cartografía de las unidades aflorantes y un muestreo selectivo de los distintos componentes litológicos observados en el área y sus alrededores. El muestreo fue apoyado por la comunidad indígena y se realizó con sondeos y apiques, donde la accesibilidad, la vegetación, el nivel freático, entre otros factores, lo permitieron. Se tomaron muestras de diferentes horizontes de los perfiles lateríticos, fragmentos de corazas ferruginosas y, donde pareció apropiado para caracterización local y disminución del peso, concentrados de los minerales pesados sobre todo de los rutilos-(Nb,Ta). En laboratorio se realizaron análisis de tamaño, forma, densidad, microscopia en luz transmitida y reflejada, microscopia electrónica y de barrido (MEB), difracción y fluorescencia de rayos $X$, espectrometría Raman, microsonda (EPMA) e ICP-MS, principalmente de los rutilos- $(\mathrm{Nb}, \mathrm{Ta})$ pero también de minerales relacionados, rocas, suelos y corazas. En esta investigación se utilizaron diferentes técnicas analíticas para poder identificar características de minerales como los rutilos y sus contenidos anómalos de $\mathrm{Nb}$, Ta y U/Pb. Por ejemplo, RAMAN permite detectar características minerales de manera no destructiva a diferencia de la difracción y fluorescencia de rayos X que requieren la pulverización de la muestra.

Tanto de los rutilos como de circones extraídos del perfil laterítico se realizó la datación $\mathrm{U} / \mathrm{Pb}$ mediante LA-ICP-MS.

\section{Recolección y preparación de muestras}

Sobre un área total de $360 \mathrm{~m}^{2}$ en los alrededores de la ocurrencia principal de rutilos se trazó una grilla de $20 \mathrm{~m}$ de espaciamiento para realizar 18 perfiles de aproximadamente $1,5 \mathrm{~m}$ de profundidad. De ellos se realizaron y muestrearon 12 perfiles de 1,5 a $2 \mathrm{~m}$ de profundidad hasta llegar al nivel freático en algunos casos y se tomaron muestras de rocas ígneas, de concentrados de batea (CB), de cristales de minerales metálicos, corazas ferruginosas y sedimentos activos, que fueron clasificadas en:

Rocas ígneas: granitos y pegmatitas que conforman los sistemas de cerros de Cachicamo y de San Roque Casuarito.

Corazas ferruginosas: corresponden a fragmentos extraídos del horizonte superficial de los perfiles del depósito de Cachicamo en la estación Col-17 (Figura 1). 
Cristales de rutilo-(Nb,Ta): fueron extraídos directamente de la coraza ferruginosa superficial del depósito en la estación Col-17.

Otros minerales pesados: obtenidos de los distintos horizontes de algunos perfiles del depósito, de sedimentos activos de Caño Cachicamo, Caño Águila (Figura 1) entre otros drenajes menores y del río Orinoco en el Raudal de Palomazón (Figura 1). También se obtuvieron concentrados de minerales pesados derivados del muestreo de rocas, diques, venas, suelos y depósitos aluviales. Las fracciones tamaño arena fueron transportadas en bolsas plásticas y luego puestas a secar a temperatura ambiente $\left(18^{\circ} \mathrm{C}\right)$ en el laboratorio.

Material suplementario: casiteritas extraídas directamente de fragmentos de corazas ferruginosas en Cerro San Roque-Casuarito, casiteritas en venas de cuarzo de sedimentos superficiales de Cerro Hormiga y cristales de columbita-tantalita, casiterita, rutilos-(Ta) provenientes de Venezuela donados por indígenas de la región.

\section{Métodos analíticos empleados}

Granulometría y medición de densidad. Unos 300 cristales de rutilo-(Nb,Ta) de la estación Col-17 fue clasificada con tamices según su tamaño (malla 1 a 7 ; malla $7 \mathrm{~d}=2,8 \mathrm{~mm}$, malla $6 \mathrm{~d}=3,36 \mathrm{~mm}$, malla $5 \mathrm{~d}=4 \mathrm{~mm}$ y malla $4 \mathrm{~d}=4,56 \mathrm{~mm}$ ). De éstos se midió su densidad, usando una balanza Sartorious modelo ED323S con una sensibilidad de 0,001 g y un kit basado en el principio de Arquímedes.

Observación en lupa binocular. En una lupa binocular Zeiss modelo Stemi 2000-C (50X) equipada con una cámara digital modelo AXIOcam ERc-5S, se distinguieron los minerales, sus relaciones de tamaño, forma y color y se separaron circones y rutilos para la datación radiométrica.

\section{Microscopía en luz transmitida y reflejada.} Se realizó petrografía/metalografía en 2 secciones delgadas pulidas de corazas ferruginosas y 6 secciones pulidas de cristales de rutilo-(Nb,Ta). Para comparación se analizaron 2 secciones de casiteritas de los cerros de San Roque y 1 de columbita-tantalita de Venezuela.

Microscopia electrónica de barrido (MEB). Imágenes SEM fueron adquiridas en el microscopio de barrido marca FEI modelo Quanta 200 de la Universidad Nacional de Colombia y laboratorios de la Universidad Federal de Rio Grande Do Sul.
Adicionalmente en los laboratorios del BGR (Servicio Geológico Alemán en Hannover) se realizaron mediciones con un equipo ESEM (Environmental Scanning Electron Microscope) de FEI Modelo Quanta 600 FEG, acoplado con un detector EDX (Apollo XL de Ametek Inc.) con $25 \mathrm{kV}$, Spot size 6 micrómetros. Aquí se utilizó también el procedimiento MLA (Mineral Liberation Analysis, Sylvester, 2012; Melcher et al., 2017) para asignar los análisis químicos a minerales correspondientes y sus porcentajes.

Fluorescencia de rayos $X$ no destructiva (pFRX). Con un equipo portátil de FRX Bruker Tracer III-V equipado con un tubo de rodio y detector Si-PIN/ SDD se determinaron los elementos a partir de $\mathrm{Mg}$ en las muestras sin necesidad de pulverización, lo que permitió escoger con mayor certeza minerales de interés para los análisis posteriores. El tiempo de medición era entre 10 a $200 \mathrm{~s}$, con voltaje entre 15-40 $\mathrm{kV}$ y corriente de 1-60 $\mu \mathrm{A}$. Para comparación de los contenidos en las muestras se mantenían las mismas condiciones, y una medición durante $60 \mathrm{~s}$ sin filtros a $40 \mathrm{kV}$ y $1 \mathrm{~mA}$ se mostró como adecuada para los rutilos. Los picos fueron analizados con el software S1PXRF, versión 3.83 y ARTAX, versión 5.3.15.1. Con la configuración adecuada se lograron límites de detección hasta $\sim 50$ ppm para elementos pesados.

Fluorescencia de rayos $X$ (FRX). En el laboratorio de Fluorescencia de rayos $X$ del Departamento de Geociencias de la Universidad Nacional de Colombia se determinaron elementos mayores y menores con el equipo PANanalyticalAXios, equipado con un tubo de rodio $\mathrm{y}$ una potencia de $4 \mathrm{~kW}$ de 9 concentrados que fueron previamente molidos en mortero de ágata, calentados a $1000^{\circ} \mathrm{C}$ para determinar pérdidas por ignición y preparadas con borato de litio a perlas por fusión a $1200^{\circ} \mathrm{C}$.

Difracción de rayos $X(D R X)$. Cristales pulverizados de rutilos-(Nb,Ta) fueron analizados en los laboratorios Alpha 1 en un difractómetro de rayos $\mathrm{X}$ marca PANalytical modelo Empyriam, en configuración Bragg-Brentano con un detector de estado sólido de alta velocidad PIXCEL 3D 2x2 para la adquisición de datos, la cuantificación se realizó por el método RIR (Reference Internal Ratio) cuando era aplicable.

Para estimar los procesos de laterización, algunas muestras de arcillas de los perfiles 5 y 9 fueron preparadas y analizadas con DRX en el Laboratorio de Suelos del Instituto Geográfico Agustín Codazzi (IGAC), utilizando difracción de rayos $\mathrm{X}$ para muestras al natural, con etilen glicol y a $550^{\circ} \mathrm{C}$. 
Espectroscopia RAMAN. Los espectros Raman inducidos por láser permiten distinguir variaciones químicas y mineralógicas como los tres polimorfos de $\mathrm{TiO}_{2}$ (rutilo, anatasa y brookita) de manera no destructiva (Hanaor y Sorrell, 2011) a microescala en muestra y sección delgada (Meinhold, 2010). Acoplado a un microscopio óptico de alta resolución se logra mapear variaciones químicas y texturales en el rango de sub-micrómetros en materiales inorgánicos y orgánicos (Nasdala et al., 2012). En este estudio se analizaron 2 secciones pulidas de rutilos-(Nb,Ta) y para comparar, 1 de casiterita y 1 de columbita-tantalita de Venezuela, en el equipo micro-Raman dispersivo del CDTEC usando un espectrómetro Nicolet Almega acoplado con un microscopio Olympus con láser de $532 \mathrm{~nm}$ apertura, de 25 micras (pinole) en una gratícula de 2400 líneas $/ \mathrm{mm}$. Los datos fueron colectados durante un tiempo de exposición de 60 s y un número de exposiciones de 5.

EPMA - Microsonda. En la microsonda JEOL JXA-8230 del Departamento de Geociencias de la Universidad Nacional de Colombia sobre secciones pulidas rutilo-(Nb,Ta) fueron analizadas semicuantitativamente mediante el mapeo de elementos mayores y cuantitativamente sobre puntos del cristal de Colombia utilizando estándares puros para Ti, Fe, Mn, Nb, Sn, Ta y W.

Datación radiométrica $\mathrm{U} / \mathrm{Pb}$ mediante $\mathrm{LA}-\mathrm{ICP}$ MS. En un equipo de ICP-MS Element 2 (Thermo Scientific) acoplado a un sistema de ablación laser Excite (Photon Machines), en el Servicio Geológico Colombiano se confirmó que un cristal de rutilo$(\mathrm{Nb}, \mathrm{Ta})$ tenía suficiente $\mathrm{U}$, Th y $\mathrm{Pb}$ para intentar realizar datación en el LA-ICP-MS de la plataforma analítica GeOHeLiS (Universidad de Rennes en Francia). Con 20 cristales de rutilo-(Nb,Ta) se preparó una sección pulida y se adquirieron fotografías MEB para la selección de los puntos de ablación. El LAICP-MS Agilent 7700x es equipado con un sistema de bombeo dual para aumentar la sensibilidad. El sistema Excimer 193 nm ESI (NWR193UC) produce un láser coherente con duración de impulsos ultra-corta ( $<5$ ns) y una célula de ablación con dos volúmenes Truline que tiene una duración de "wash-out" de menos de 0,2 segundos, completamente controlado por ordenador. Para el óptimo posicionamiento del láser en la muestra se tomaron fotografías MEB de los cristales de rutilo$(\mathrm{Nb}, \mathrm{Ta})$ escogiendo las zonas más homogéneas que no presentaron inclusiones o las presentaron en muy baja proporción. Debido al tamaño de los cristales y el poco contenido de $\mathrm{U}$ y $\mathrm{Pb}$ la ablación de los granos con láser fue realizada en spots de 65 micras, utilizando una frecuencia de $5 \mathrm{~Hz}$ y una intensidad de $8,44 \mathrm{~J} / \mathrm{cm}^{2}$. El material evaporado fue cargado por un flujo de $\mathrm{He}$ $(\sim 0,40 \mathrm{~L} / \mathrm{min})$ y $\operatorname{Ar}(\sim 0,90 \mathrm{~L} / \mathrm{min})$.

En todos los análisis se utilizaron los patrones R10 (1090 Ma) y R19 (489,5 $\pm 0,9$ Ma, Zack et al., 2011) descritos en inicialmente en Zack et al. (2004) y utilizados en Bracciali et al. (2013), para la corrección de la deriva del equipo, así como para controlar el fraccionamiento entre los isótopos de $\mathrm{U}$ y $\mathrm{Pb}$. Se puede encontrar información adicional sobre el protocolo analítico en Boutin et al. (2016).

Adicionalmente fueron analizadas las relaciones isotópicas $(\mathrm{U}, \mathrm{Th}, \mathrm{Pb})$ en circones detríticos extraídos de los horizontes A (coraza ferruginosa) y C (regolito caolinizado) del Perfil 1 de la estación Col-17 con el fin de determinar así las edades máximas y mínimas de estos en el depósito. Para los análisis fueron utilizados los estándares de referencia primario GJ-1 con una

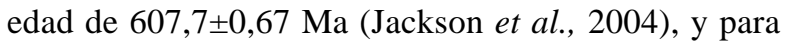
control de calidad, el estándar Plesovice con una edad de 337 Ma (Sláma et al., 2008). La ablación láser en $\sim 90$ circones fue realizada en spots de 30 micras, con una frecuencia de $3 \mathrm{~Hz}$ e intensidad de 8,44 J/ $\mathrm{cm}^{2}$. El material evaporado fue cargado por un flujo de $\mathrm{He}(\sim 0,40 \mathrm{~L} / \mathrm{min})$ y $\operatorname{Ar}(\sim 0,90 \mathrm{~L} / \mathrm{min})$. En todos los análisis se utilizaron los patrones GJ1 y Plesovice para la corrección de la deriva del equipo, y del fraccionamiento entre los isótopos de $\mathrm{U}$ y $\mathrm{Pb}$. Se puede encontrar información adicional sobre el protocolo analítico en Manzotti et al. (2015). Los datos U/Pb fueron graficados utilizando Isoplot 3,75 (Ludwig, 2012).

\section{Resultados}

\section{Geología local}

Las unidades litológicas reconocidas en el área de estudio y los puntos de muestreo fueron dibujadas en un mapa (Figura 2) a partir de las observaciones y descripciones de campo, el mapeo de superficie fue apoyado en la orto imagen corregida para el Departamento del Vichada. 


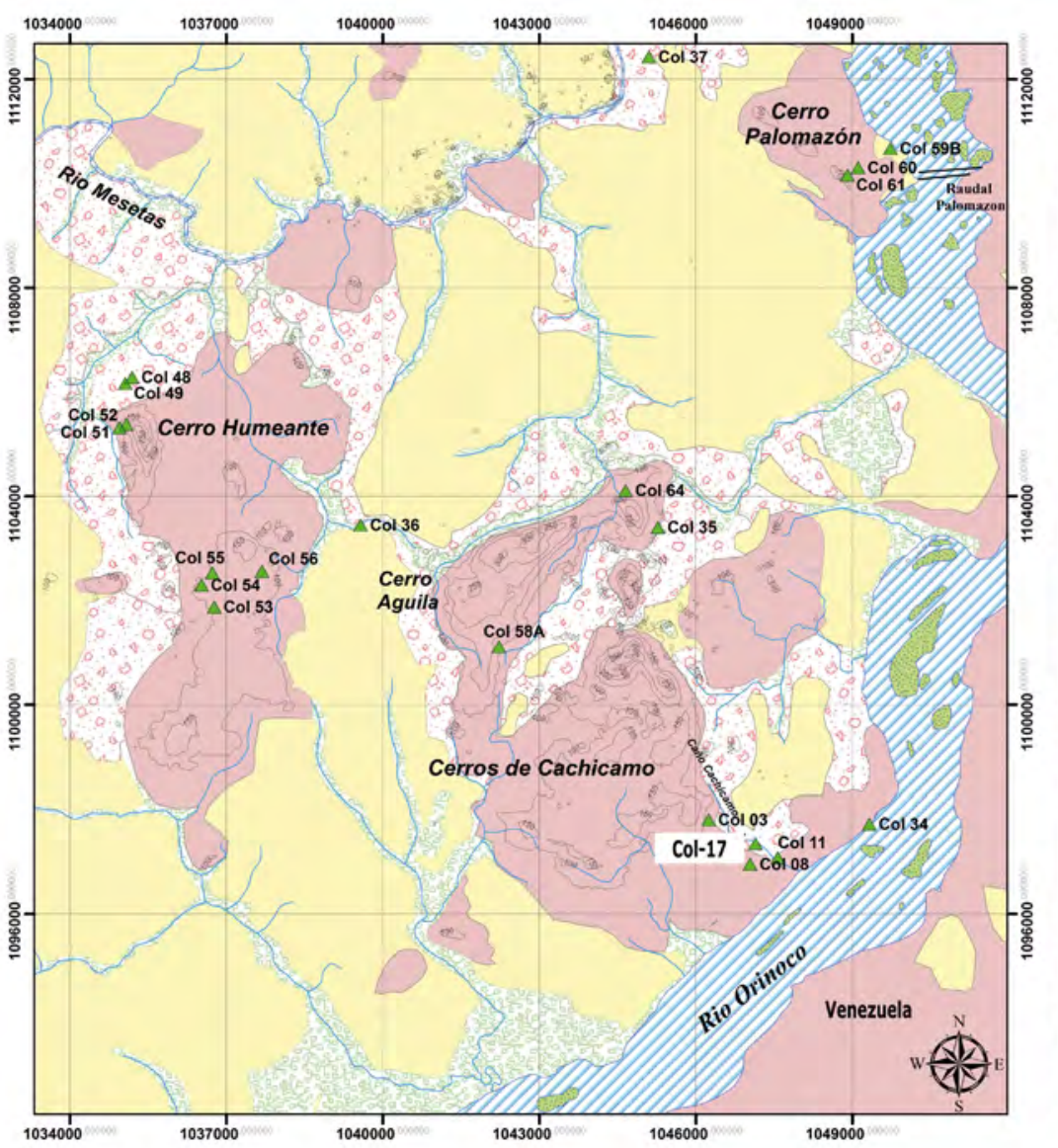

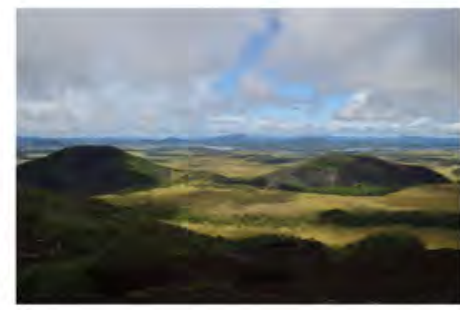

A

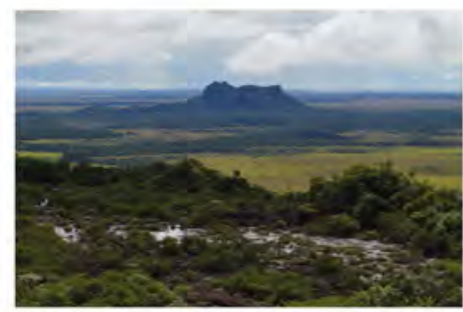

B

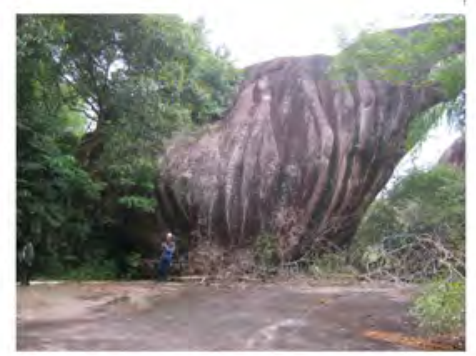

C

\section{Leyenda}

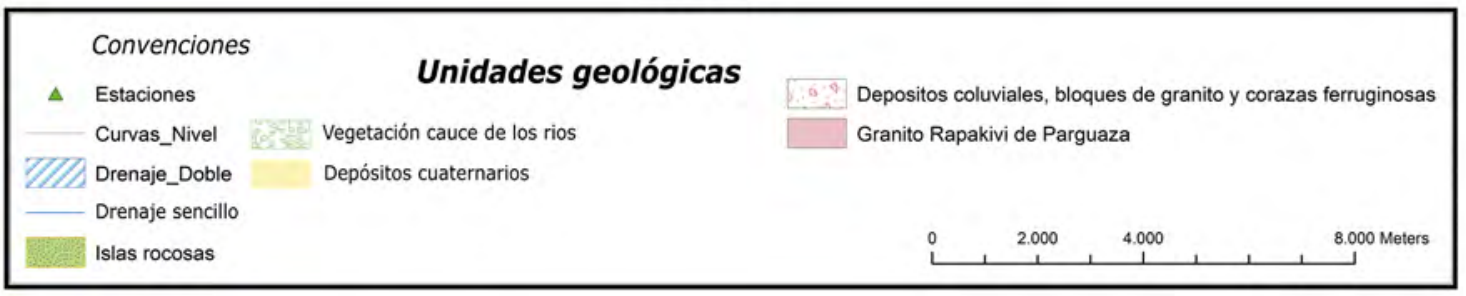

Figura 2. Mapa de la zona de estudio mostrando las unidades geológicas aflorantes en el área en especial cerros graníticos aflorantes separados por drenajes llenados por sedimentos a la orilla izquierda del río Orinoco y algunas de las estaciones estudiadas (ver texto). Los rutilos-(Nb,Ta) de este estudio fueron recolectados en la estación Col-17. A la derecha fotografías mostrando rasgos geomorfológicos: A. Vista hacia el río Orinoco desde la estación Col-58A. B. Vista hacia Cerro Humeante desde la estación Col-64. C. Bloque de granito con textura rapakivi formando parte del coluvión en la estación Col-03.

Basamento cristalino del Granito Rapakivi de Parguaza. Aflora conformando un sistema de cerros aislados de morfología redondeada y de pendientes fuertemente inclinadas, con alturas máximas de $400 \mathrm{msnm}$, de los cuales sobresalen los cerros de Cachicamo, Humeante, Águila, Casuarito, San Roque, Dagua, Zamuro, Murciélago y otros de menor altura como Palomazón, Conejo y Katano que forman parte del extenso Granito de Parguaza en esta zona (Figuras
1 y 2). Presentan textura rapakivi con fenocristales ovoides de feldespato potásico de hasta $10 \mathrm{~cm}$ de diámetro, con inclusiones de biotita formando textura poiquilítica. Su composición mineral aproximada es de cuarzo $25 \%$, feldespato potásico $60 \%$, plagioclasa $10 \%$, biotita $15 \%$, pero hay también variaciones de granitos con cristales finos. Los cuerpos rocosos están cortados por un sistema de diques pegmatíticos de distintos espesores, aplitas y venas de cuarzo 
en arreglos enrejados. Los diques parecen estar controlados estructuralmente, rellenando pequeñas diaclasas y fallas con orientación preponderante NE, las venas no presentan una orientación preferencial y parecen estar rellenando diaclasas. Las rocas ígneas leucocráticas de textura rapakivi se presentan como un cuerpo homogéneo sin texturas de flujo y en algunos casos con meteorización avanzada.

Corazas ferruginosas. En la parte norte del Vichada (Figura 1) afloran entre los 75 y $100 \mathrm{~m}$ de altura de occidente a oriente corazas ferruginosas, marcando una paleo-superficie indicando un proceso de laterización extenso, sus mayores espesores se observaron en la divisoria de aguas de los ríos Muco-Bita, MucoJuriepito y Juriepe-Meta, desapareciendo hacia el Este en el límite con el río Orinoco. Estas corazas presentan diferencias de forma y composición, expresadas en la relación de matriz-cemento, en los contenidos de cuarzo, la asociación mineral y el tamaño de los fragmentos que las conforman.

En el área de estudio no fue posible reconocer rocas sedimentarias del Cenozoico y la formación de corazas ferruginosas ocurre directamente sobre rocas del basamento o sobre depósitos coluvio-aluviales conformados por sedimentos de distinta procedencia. El espesor de la coraza ferruginosa en el área es muy variable sin superar los 2 m y su extensión está limitada por pequeños afloramientos del granito con textura rapakivi (Figura 2) de los Cerros de Cachicamo con dirección NE desapareciendo gradualmente hacia las orillas del río Orinoco.

\section{Depósitos cuaternarios no consolidados y} sedimentos activos. Los coluviones en cercanías al área de estudio están conformados por bloques de granito de grandes dimensiones (Figura 2) que disminuyen de tamaño a medida que se alejan del piedemonte; estos bloques conforman barreras topográficas (microcuencas) que son posteriormente rellenadas por fragmentos de roca, de corazas ferruginosas, de diques pegmatíticos, de diques y venas de cuarzo y gravas.

En la llanura se presentan gravas finas y arenas cuarzosas con fragmentos de pisolitos de corazas ferruginosas. Los sedimentos activos corresponden a los cauces de los drenajes secundarios que nacen de los cerros principales y están compuestos por arenas finas de cuarzo y minerales pesados, principalmente ilmenita, magnetita y circón, similares a los que se encuentran en las llanuras de inundación provenientes del río Orinoco y de drenajes intermitentes y secundarios.

\section{Caracterización del perfil laterítico de Cachicamo}

De los 18 perfiles de aproximadamente $1,5 \mathrm{~m} \mathrm{de}$ profundidad alrededor de la ocurrencia principal de rutilos en un área total de $360 \mathrm{~m}^{2}$ en los primeros 12 perfiles se demarcaron cuatro horizontes reconocibles por su composición, color, y granulometría de tope a base de la siguiente manera (ejemplo en Figura 3):

Horizonte 0: horizonte superficial compuesto por sedimentos activos y materia orgánica; se observa el desarrollo incipiente de suelo que no alcanza los $5 \mathrm{~cm}$ de profundidad. En cercanías a la llanura de inundación de Caño Cachicamo se presentan arenas cuarzosas con ilmenita, magnetita y circón. En ocasiones se observan fragmentos de la coraza ferruginosa y pisolitos de hematita-magnetita.

Horizonte A: coraza ferruginosa; horizonte de color naranja a marrón compuesto por una capa superficial endurecida de oxi- e hidróxidos de hierro de hasta $60 \mathrm{~cm}$ de espesor, texturalmente presenta formas irregulares y cavidades en forma de canales rellenadas por materia orgánica y arenas de grano fino. Ha sido definido como el horizonte guía por su extensión superficial y debido a que localmente se identificaron incluidos cristales de rutilo-(Nb,Ta).

Horizonte B: nivel transicional laterítico; horizonte de color amarillo a ocre compuesto por fragmentos de la coraza ferruginosa suprayaciente, fragmentos de cristales de cuarzo, roca y feldespato en una matriz areno-arcillosa que aumenta en proporción con la profundidad; en algunos perfiles este horizonte alcanza hasta $90 \mathrm{~cm}$ de espesor.

Horizonte C: regolito caolinizado; horizonte de color gris a blanco compuesto por fragmentos de granito rapakivi, fragmentos de cuarzo y feldespato en una matriz 40\% arenosa con cristales de cuarzo, ilmenita, magnetita y circón y un $20 \%$ de la fracción arcillosa compuesta principalmente por caolinita. 


\section{Estación Col-17 Pozos 1-12}
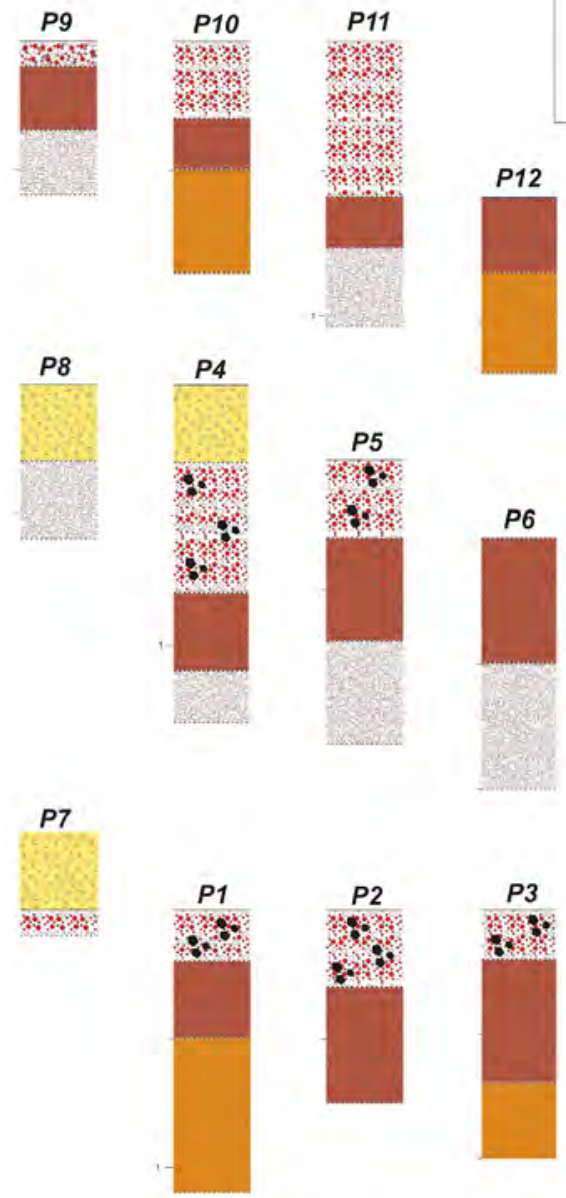

Figura 3. Perfiles del depósito que muestran el horizonte guía conformado por una capa de $60 \mathrm{~cm}$ máximo de espesor de una coraza ferruginosa con cristales de rutilos-(Nb,Ta) incluidos.

\section{Caracterización de la coraza ferruginosa de Cachicamo}

Las corazas ferruginosas muestran una gran variación textural y composicional, en su matriz y el armazón (Figura 4).

Matriz: compuesta de hematita y goethita, arcillas y cristales finos de cuarzo, circón, ilmenita y magnetita. Las diferencias de coloración permiten definir una proporción variada de óxidos e hidróxidos de hierro, mientras de $\mathrm{Mn}$ o Al no fueron observados. La asociación hematita-limonita-goethita que compone la matriz muestra un estado avanzado de los procesos de lixiviación ocurridos en la formación de lateritas y horizontes ferruginosos.
Armazón: compuesto por pisolitos de óxi-hidróxidos de hierro como hematita, limonita y goethita con núcleos de cuarzo y circón, además de fragmentos de granito, diques de cuarzo, feldespato y cuarzo en ocasiones mayores a $3 \mathrm{~cm}$ y en menor proporción cristales de rutilo-(Nb,Ta) de hasta $3 \mathrm{~cm}$. En general la textura y composición lítica de las corazas varía en cortas distancias como se pudo observar en la estación Col-17F (Figura 4H) a unos $300 \mathrm{~m}$ de la ocurrencia principal, donde se presentan grandes bloques color marrón de forma arriñonada que no preservan cristales de rutilo-( $\mathrm{Nb}, \mathrm{Ta})$ y que podrían constituir otra fuente de sedimentos incluidos en la actual coraza. 

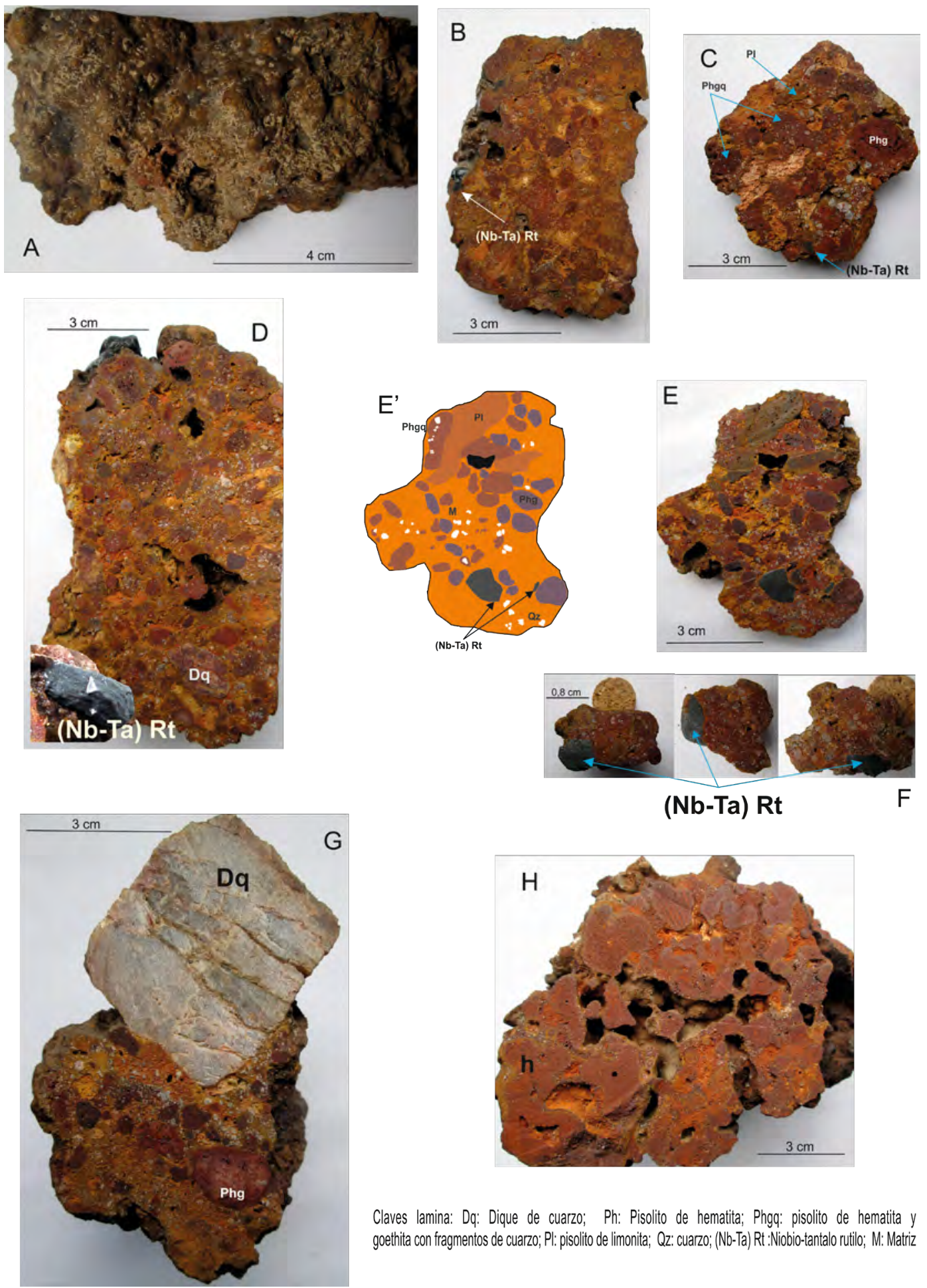

(Nb-Ta) Rt

Figura 4. Rutilos-(Nb,Ta) en corazas ferruginosas asociadas a depósitos coluviales sobre rocas del Granito de Parguaza en el piedemonte de los Cerros de Cachicamo, estación Col-17. A. Apariencia externa de fragmento de corazas mostrando un predominio de la matriz de óxidos e hidróxidos de hierro. B. Corte transversal mostrando la asociación mineral principal compuesta por pisolitos, nótese un cristal de rutilo de $0,8 \mathrm{~cm}$ de diámetro. C. Fragmentos de pisolitos, cuarzo y cristal de rutilo(Nb,Ta) de 0,4 cm de diámetro. D. E. y F. Cristales de rutilo-(Nb,Ta) de hasta $3 \mathrm{~cm}$ y pisolitos en una matriz de oxi-hidróxidos de Fe. G. Fragmento retrabajado de dique de cuarzo y feldespato de $5 \mathrm{~cm}$ de diámetro incluido en coraza. H. Coraza ferruginosa de la estación Col-17F a 300 m del depósito, nótese la textura arriñonada y la ausencia de pisolitos. 


\section{Caracterización Mineralógica del rutilo- (Nb,Ta) de Cachicamo}

Tamaño, forma, color, densidad y correlación con composición química (pFRX). Los rutilos$(\mathrm{Nb}, \mathrm{Ta})$ se presentan en cristales de hasta $4 \mathrm{~cm}$ de formas predominantemente subangulares conservando algunas facetas, de color gris-azulado a negro con brillo metálico, raya gris verdosa, no magnéticos. Los cristales ocupan todo el espectro granulométrico (Figura 5A) desde malla 1 hasta malla 7, con los mejores ejemplares para mediciones adicionales entre malla $7(\mathrm{~d}=2,8 \mathrm{~mm})$, malla $6(\mathrm{~d}=3,36 \mathrm{~mm})$ malla $5(\mathrm{~d}=4 \mathrm{~mm})$ y malla $4(\mathrm{~d}=4,56 \mathrm{~mm})$. No se observó una correlación directa entre tamaño de granos y densidad.

La densidad medida de 250 granos de rutilo-(Nb,Ta) varía entre 4,2 y 5,9 g/ $/ \mathrm{cm}^{3}$ con un promedio de 4,8 $\mathrm{g} / \mathrm{cm}^{3}$ (histograma Figura 5B). Considerando que la densidad calculada de rutilo puro es $4,21 \mathrm{~g} / \mathrm{cm}^{3}$, las mayores densidades medidas se asocian a contenidos más altos de elementos pesados, especialmente de $\mathrm{Nb}$ y Ta. En la Figura 5C se muestran los espectros de Ti, $\mathrm{Fe}, \mathrm{Mn}, \mathrm{Nb}$ y Ta de un rutilo con densidad 3,4 $\mathrm{g} / \mathrm{cm}^{3}$ en rojo (Col-17 malla 6 A3) y en verde de un rutilo con densidad 5,9 g/ $\mathrm{cm}^{3}$ (Col-17 malla 6 C1). Como un resultado se destaca que solamente cuando se miden los rutilos bajo las mismas condiciones (aquí pXRF con $40 \mathrm{kV}, 1 \mu \mathrm{A}$ sin vacío ni filtros durante 60 segundos cada uno) se observa en relación con los espectros normalizados a Ti un fuerte aumento de $\mathrm{Nb}$ y Ta en la muestra de mayor densidad; y también el aumento paralelo de Fe y Mn confirman su asociación con inclusiones de columbita y no como fases de ilmenita en los rutilos. Para mayor claridad no se muestran en la Figura $5 \mathrm{C}$ los elementos traza identificados ( $\mathrm{Sn}, \mathrm{Ca}$, $\mathrm{V}, \mathrm{Cr}, \mathrm{Zr}, \mathrm{W}$ y Nd).
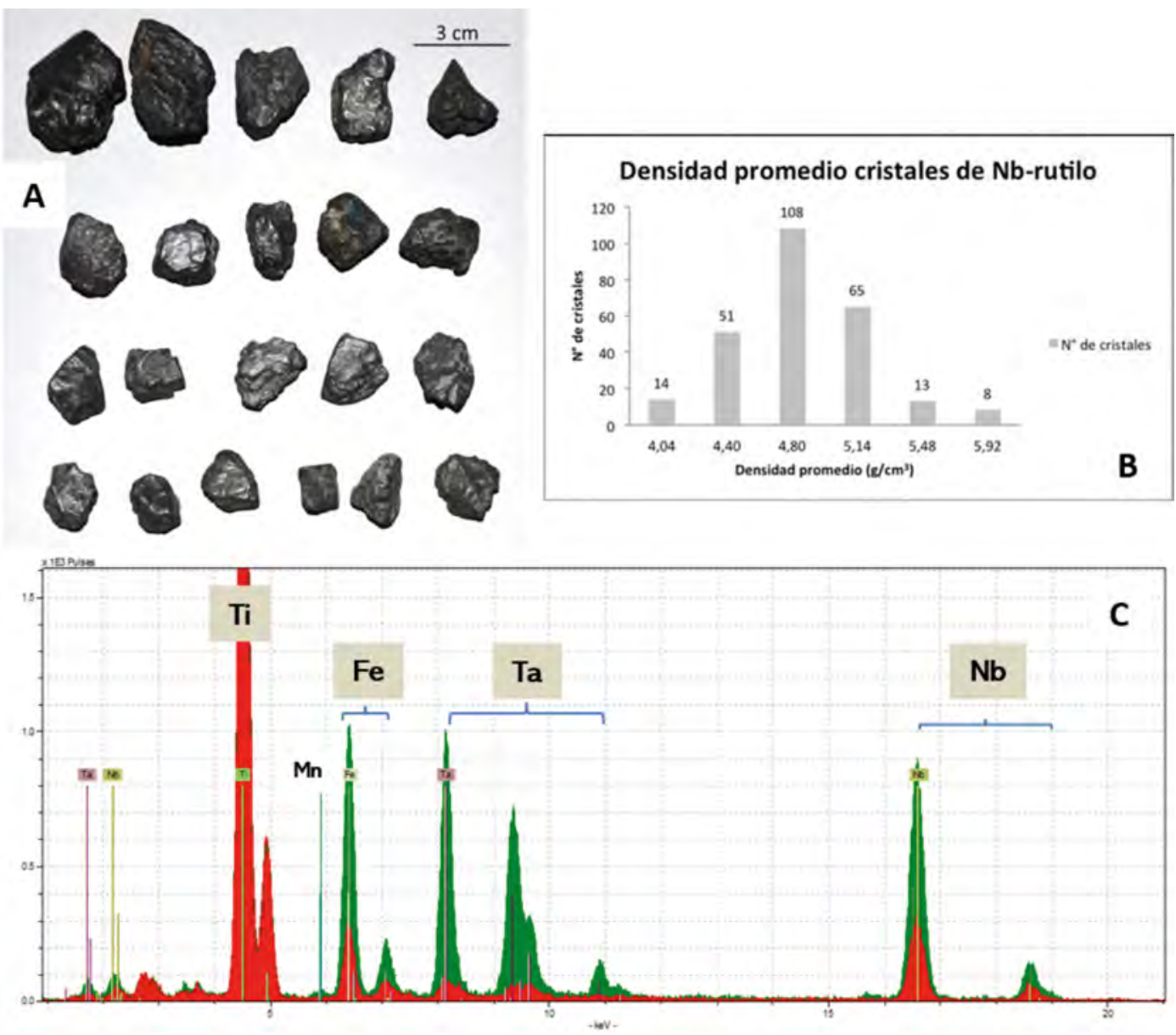

Figura 5. A. Cristales de rutilo-(Nb,Ta) extraídos de la coraza ferruginosa aflorante en el depósito de Cachicamo. B. Histograma de densidades medidas indicando el aumento de elementos pesados en los rutilos. C. Espectros de FRX de dos rutilos-(Nb,Ta) con diferentes densidades (Col-17 malla 6 A3, 3,4 g/ $\mathrm{cm}^{3}$ en rojo y Col-17 malla 6 C1, 5,9 g/cm ${ }^{3}$ en verde). 
Metalografía. En las 6 secciones pulidas de rutilos(Nb,Ta) se reconocieron las principales características en luz reflejada (Tabla 1). Los cristales en forma de agregados masivos se diferencian por una reflectancia relativamente alta, la anisotropía con nicoles cruzados es especialmente fuerte en los límites donde la extinción exhibe texturas ramificadas, de enrejado e interdigitada de contactos sinuosos y rectos similares a maclas simples y de "rodillas" con el plano de macla (101) típicas (Figura 6), probablemente debido a dislocaciones durante el crecimiento de los rutilos. Los reflejos internos muy marcados en aceite los distinguen de otros minerales como magnetitas.

En general los cristales de rutilo-(Nb,Ta) presentan inclusiones orientadas de hasta 200 micras de columbita-tantalita y casiterita. En algunos se observan pequeñas inclusiones de circón. En las fracturas de origen mecánico durante los procesos de laterización se han precipitado goethita-hematita. Pero en general, los rutilos y sus inclusiones parecen no haber sido alterados por procesos posteriores a su formación primaria (magmática a hidrotermal).

Tabla 1. Características metalográficas de rutilo-(Nb,Ta).

\begin{tabular}{|c|c|c|c|c|c|c|}
\hline \multirow[t]{2}{*}{ Mineral } & $\begin{array}{l}\text { Reflectancia y } \\
\text { color en PPL }\end{array}$ & $\begin{array}{c}\text { Pleocroísmo en } \\
\text { PPL } \\
\end{array}$ & \multirow[t]{2}{*}{$\begin{array}{c}\text { Anisotropía en } \\
\text { XPL }\end{array}$} & \multirow{2}{*}{$\begin{array}{l}\text { Reflexiones } \\
\text { internas en } \\
\text { XPL }\end{array}$} & \multirow[t]{2}{*}{ Maclas } & \multirow[t]{2}{*}{$\begin{array}{c}\text { Asociación } \\
\text { mineral }\end{array}$} \\
\hline & Aire & Aire & & & & \\
\hline $\begin{array}{l}\text { Rutilo- } \\
\text { (Nb,Ta) }\end{array}$ & $\begin{array}{c}\text { Blanco metálico } \\
\text { con una tonalidad } \\
\text { grisácea - café }\end{array}$ & No pleocróico & $\begin{array}{c}\text { Alta; } \\
\text { coloraciones } \\
\text { café verdoso u } \\
\text { oliva oscuro }\end{array}$ & $\begin{array}{l}\text { En aire débil, en } \\
\text { aceite fuerte }\end{array}$ & $\begin{array}{c}\text { Presencia } \\
\text { de maclas y } \\
\text { zonaciones }\end{array}$ & $\begin{array}{c}\text { Rutilo, } \\
\text { cuarzo, circón }\end{array}$ \\
\hline
\end{tabular}
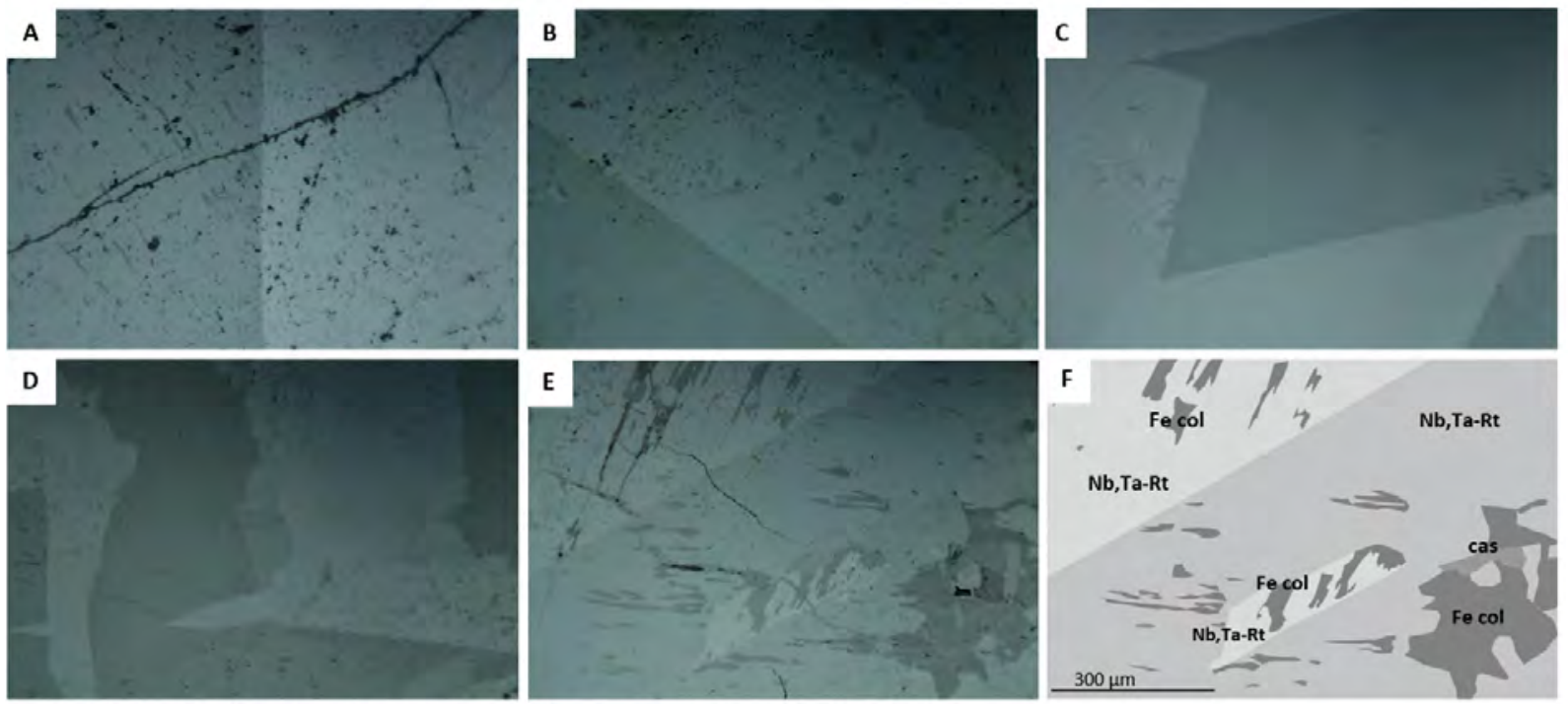

Claves fotografias: $\mathrm{Nb}, \mathrm{Ta}-\mathrm{Rt}=$ rutilo con niobio y tantalio; $\mathrm{Cas}=$ casiterita; $\mathrm{Fe}$-Col $=$ ferrocolumbita

Figura 6. Microfotografías en luz reflejada, XPL, en aire, de rutilos-(Nb,Ta) de la estación Col-17. A. Maclas e inclusiones orientadas. B. Macla similar a la de Carlsbad e inclusiones masivas. C. Textura interdigitada con bordes rectos. D. Textura interdigitada con bordes sinuosos. E. Inclusiones orientadas de diferentes cristales. F. Fotografía E digitalmente procesada para resaltar las diferentes fases minerales con distintas tonalidades grises y la extinción de fases similares.

MEB -EDX. En las imágenes MEB de una muestra de coraza ferruginosa (Col-17-Cf, Figura 7) se observa la relación rutilo-(Nb,Ta) y la coraza ferruginosa. También en las magnificaciones no se ven bordes de reacción entre ambos. Mediante análisis EDX se reconocieron las fases minerales circón, ilmenita y cuarzo en una matriz de óxidos e hidróxidos de Fe como los principales componentes de la coraza ferruginosa. En el cristal de rutilo-(Nb,Ta) se observan inclusiones de hasta $250 \mathrm{~mm}$ de columbita de formas irregulares pero en gran parte orientadas a lo largo de planos cristalográficos que en la mayoría de los casos están asociadas con inclusiones más pequeñas de casiterita. 


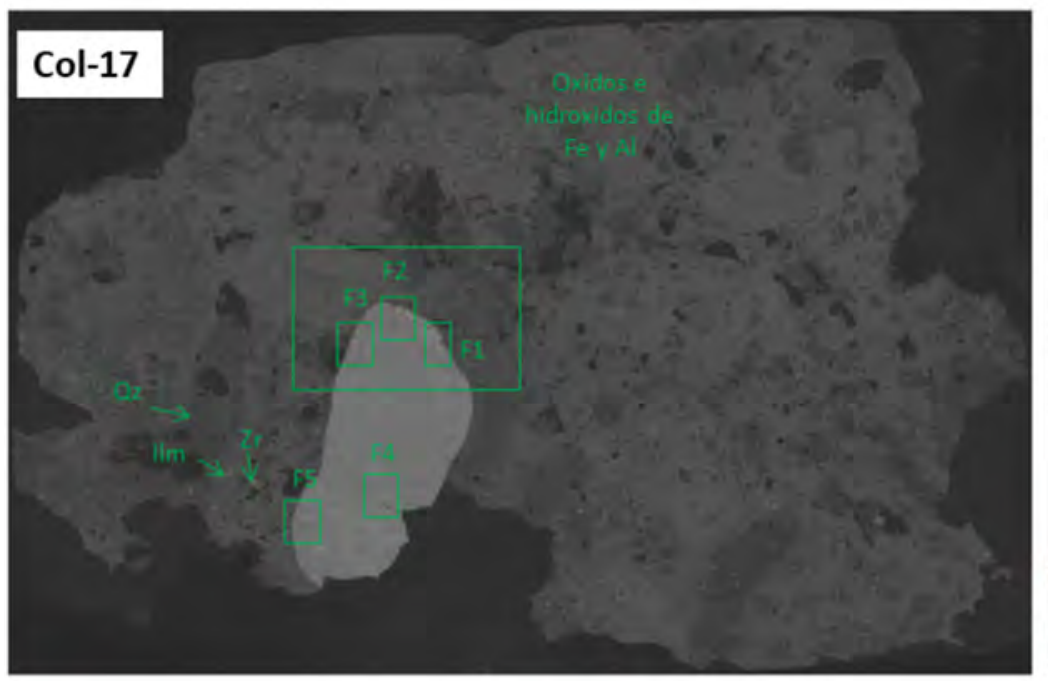

\section{Rutilo-(Nb,Ta) en coraza ferruginosa (Col-17)}
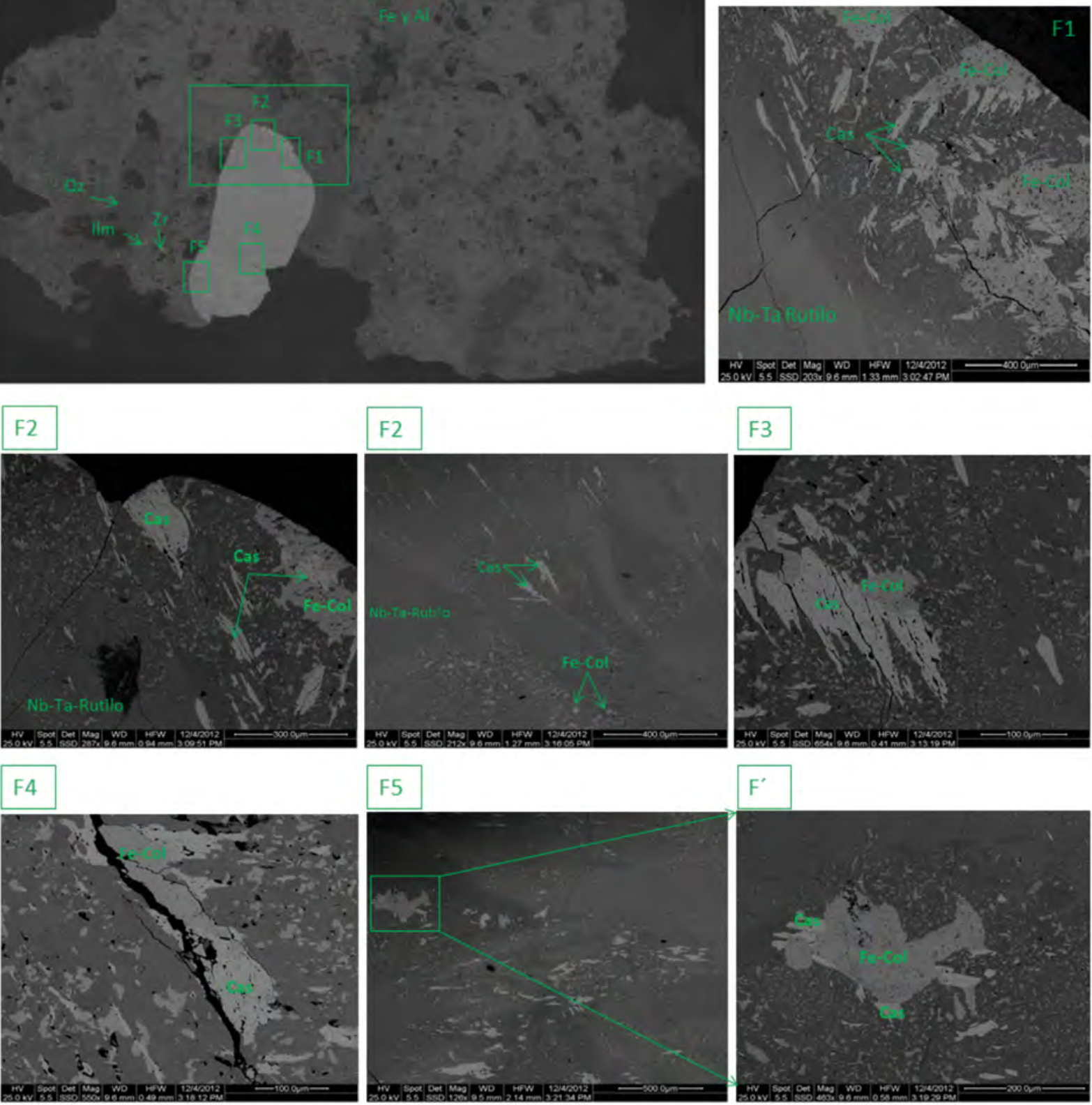

Claves fotografias: $\mathrm{Nb}$-Ta rutilos = rutilos con contenidos de niobio y tantalio; Fe-col = ferro-columbita; Cas = casiterita, $Q z=c u a r z o ; ~ I m=$ ilmenita; $Z r=$ zircón.

Figura 7. Fotografía MEB (Col-17) de coraza ferruginosa con un cristal de rutilo-(Nb,Ta) y algunos granos de cuarzo, circón e ilmenita. Los campos F1-F5 corresponden a las microfotografías del cristal de rutilo-( $\mathrm{Nb}, \mathrm{Ta})$ donde se ven las inclusiones más claras de columbita y casiterita, a menudo con crecimientos orientados. La escala varía desde 500 a $100 \mu$ m. F' muestra en detalle de las inclusiones (columbita y casiterita) de la Figura F5. 
FRX en polvo. El análisis químico con FRX del mineral pulverizado (Tabla 2) refleja tanto la incorporación de otros cationes con radios iónicos similares en la estructura cristalina de los rutilos como también una variedad de inclusiones o exsoluciones que se mantiene en proporción general donde dominan además de Ti (rutilos), Nb y Ta (columbitatantalita) seguidos por Sn (casiteritas) y se mantienen \pm constantes $\mathrm{Fe}_{2} \mathrm{O}_{3}$ cerca de $10 \%$ y $\mathrm{Mn}_{3} \mathrm{O}_{4}$ y $\mathrm{WO}_{3}$ entre $0,3-0,5 \%$. Los rutilos-(Nb,Ta) presentan una composición promedio en \% en peso del $53 \% \mathrm{TiO}_{2}$, $14 \% \mathrm{Nb}_{2} \mathrm{O}_{5}$ y $13 \% \mathrm{Ta}_{2} \mathrm{O}_{5}$. Expresando por ejemplo en las mediciones de la muestra Rutilo coraza (Col17-C-III) de la Tabla 2 se puede calcular una formula aproximada de Tio,64 $\mathrm{Fe}_{0,12} \mathrm{Mn}_{0,01} \mathrm{Nb}_{0,11} \mathrm{Ta}_{0,07} \mathrm{Sn}_{0,03} \mathrm{O}_{2}$. La carga catiónica insuficiente calculada se aumenta todavía si se asume todo hierro como $\mathrm{Fe}^{2+}=\mathrm{FeO}(\mathrm{el}$ estado de oxidación más probable) en vez de $\mathrm{Fe}^{3+}$ (= $\mathrm{Fe}_{2} \mathrm{O}_{3}$ ) como expresado en la Tabla 2. Una parte de Fe y Mn forma parte de las inclusiones de columbita que concentran también la mayor parte de $\mathrm{Ta}$ y $\mathrm{Nb}$. Pero la serie de los rutilos puede incorporar varios otros cationes hasta formar miembros finales diferentes en la estructura tetragonal de rutilo. No se han evidenciado magnetitas y solamente muy pocas ilmenitas en las muestras, ni signos de leucoxenización, así que el contenido alto de $\mathrm{Fe}$ se debe probablemente a una sustitución acoplada $\mathrm{Ti}^{4+}-\mathrm{Fe}^{3+}-\mathrm{Fe}^{2+}-\mathrm{Nb}^{5+}-\mathrm{Ta}^{5+}$ (ej. $\left.\mathrm{Fe}^{3+}+\mathrm{Nb}^{5+} \leftrightarrow 2 \mathrm{Ti}^{4+}\right)$ en los rutilos y parcialmente en las columbitas-(Fe). La composición química de los rutilos puede variar considerablemente, influenciando propiedades como la densidad.

Tabla 2. Resultados de análisis FRX (\% en peso) de cristales de rutilo-(Nb,Ta) con inclusiones de columbita y casiterita. *Por debajo del límite de detección.

\begin{tabular}{|c|c|c|c|c|c|c|c|c|c|c|c|c|c|c|c|}
\hline Nombre & $\mathrm{SiO}_{2}$ & $\mathrm{TiO}_{2}$ & $\mathrm{Al}_{2} \mathrm{O}_{3}$ & $\mathrm{Fe}_{2} \mathrm{O}_{3}$ & $\mathrm{Mn}_{3} \mathrm{O}_{4}$ & $\mathrm{CaO}$ & $\mathbf{P}_{2} \mathbf{O}_{5}$ & $\mathbf{V}_{2} \mathbf{O}_{5}$ & $\mathrm{ZrO}_{2}$ & $\mathrm{BaO}$ & $\mathrm{HfO}_{2}$ & $\mathrm{Nb}_{2} \mathrm{O}_{5}$ & $\mathrm{SnO}_{2}$ & $\mathbf{T a}_{2} \mathbf{O}_{5}$ & $\mathrm{WO}_{3}$ \\
\hline $\begin{array}{l}\text { Rutilo coraza } \\
\text { (Col-17-C- } \\
\text { III) }\end{array}$ & 0,29 & 52,95 & 0,22 & 10,11 & 0,46 & $*$ & 0,03 & $*$ & 0,19 & $*$ & $*$ & 15,62 & 3,97 & 15,65 & 0,51 \\
\hline $\begin{array}{c}\text { Rutilos (Col- } \\
\text { 17-A-C) }\end{array}$ & $*$ & 58,38 & 0,16 & 9,08 & 0,31 & $*$ & $*$ & $*$ & 0,13 & $*$ & $*$ & 14,04 & 3,66 & 13,75 & 0,45 \\
\hline $\begin{array}{c}\text { Segunda } \\
\text { ocurrencia } \\
\text { (Col-17-B-C) }\end{array}$ & $*$ & 54,97 & 0.45 & 9,52 & 0,46 & $*$ & 0,05 & $*$ & 0,16 & $*$ & $*$ & 15,04 & 3,76 & 15,99 & 0,50 \\
\hline $\begin{array}{l}\text { Cristal Rutilo } \\
\text { (Col-17-C-I) }\end{array}$ & $*$ & 53,79 & 0,43 & 9,51 & 0,45 & $*$ & 0,05 & * & 0,16 & 0,03 & 0,10 & 15,13 & 3,82 & 15,99 & 0,50 \\
\hline $\begin{array}{l}\text { Concentrado } \\
\text { (Col-17-C-II) }\end{array}$ & 0,39 & 57,37 & 0,13 & 8,74 & 0,39 & $*$ & $*$ & 0,30 & 0,17 & * & $*$ & 14,41 & 3,82 & 13,77 & 0,49 \\
\hline $\begin{array}{c}\text { Rutilos 3/8”-4 } \\
\text { (Col-17-C- } \\
\text { III) }\end{array}$ & 0,29 & 57,09 & 0,32 & 9,49 & 0,33 & $*$ & $*$ & 0,19 & 0,14 & $*$ & 0,06 & 14,02 & 4,34 & 13,27 & 0,43 \\
\hline $\begin{array}{l}\text { Rutilos > 1/2" } \\
(\text { Col-17-C-V) }\end{array}$ & 0,29 & 57,35 & 0,40 & 8,63 & 0,34 & 0,05 & $*$ & 0,31 & 0,12 & $*$ & $*$ & 14,49 & 3,96 & 13,66 & 0,38 \\
\hline $\begin{array}{c}\text { Rutilos } 1 / 2 ” \text { a } \\
\text { 3/8” (Col-17- } \\
\text { C-V) }\end{array}$ & 0,22 & 56,83 & 0,06 & 8,75 & 0,33 & $*$ & $*$ & 0,33 & 0,13 & $*$ & $*$ & 14,65 & 3,95 & 14,35 & 0,38 \\
\hline (Col-17-C-V) & 0,29 & 57,92 & 0,11 & 8,23 & 0,29 & $*$ & $*$ & 0,29 & 0,13 & $*$ & $*$ & 13,54 & 5,92 & 12,84 & 0,44 \\
\hline
\end{tabular}

Los datos obtenidos de los análisis FRX fueron normalizados y graficados en un diagrama ternario (Ti, Ta y Nb) (Figura 8) y comparados con datos bibliográficos de microsonda realizados a cristales de rutilos $(\mathrm{Nb})$ provenientes de pegmatitas en Canadá y Venezuela, con menores o mayores concentraciones de Ta y Nb. 


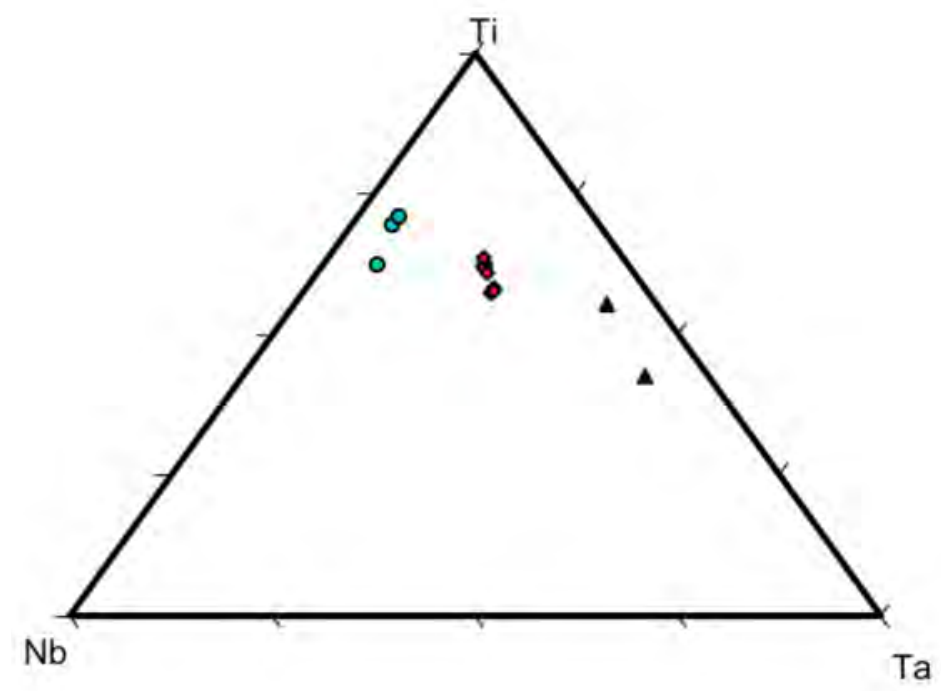

Figura 8. Diagrama ternario (Ti, Nb, Ta) de datos de FRX de rutilos de Cachicamo (rombos rojos) y de microsonda de rutilos(Nb) de Canadá (circulo azul, Cerny et al., 1981) y Venezuela (triángulos negros, Aarden y Davidson, 1977). Los rutilos-(Nb,Ta) de Cachicamo muestran una composición intermedia de $\mathrm{Nb}$ y Ta, respecto a las muestras comparadas.

DRX. Los difractogramas (Figura 9) de 5 muestras pulverizadas confirman la existencia de varias fases sólidas. La matriz en promedio presenta un $78 \%$ de rutilo-(Nb) y las inclusiones un $18 \%$ de columbitatantalita y un $4 \%$ de casiterita. Los valores $d_{h k l}$ de los 3 primeros picos con mayor intensidad de rutilo(Nb) $\left(\mathrm{Ti}_{0,7} \mathrm{Nb}_{0,2} \mathrm{Fe}^{2+}{ }_{0,2} \mathrm{O}_{2}\right)$ son $3,23(1), \quad 1,687(0,9)$,
$2,48(0,8) \AA$, mientras para un rutilo puro los valores $d_{\text {hkl }}$ son $3,245(1), 1,687(0,5), 2489(0,41) \AA$ (en paréntesis la intensidades relativas $\mathrm{I} / \mathrm{I}_{0}$ ). En la literatura consultada (ej. Meinhold, 2010) no se han reportado desplazamientos de algunos picos (hkl) por la incorporación de otros cationes y una consiguiente variación de los valores $\mathrm{d}_{\mathrm{hkl}}$.

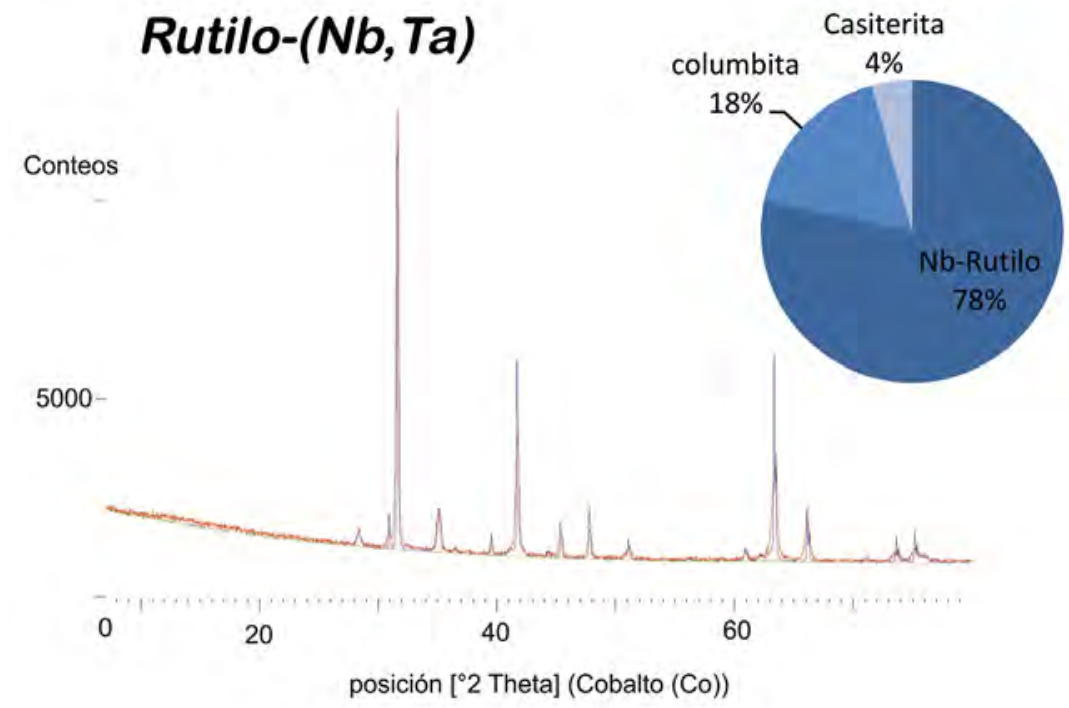

Figura 9. Difractograma obtenido de los pulverizados de cristales de rutilo-(Nb,Ta) mostrando los picos principales en la posición $2 \theta$. La gráfica de torta muestra el porcentaje de las fases minerales cuantificadas mediante el refinamiento Rietveld que corresponderían a una matriz de rutilo-(Nb) e inclusiones de columbita-(Fe) y casiterita. 
Microscopia Raman. Los espectros Raman de cristales de rutilos-(Nb,Ta) (Figura 10) de la muestra Col-17-C-I muestran los principales números de onda en las bandas Raman 829, 631, 443 y $237 \mathrm{~cm}^{-1}$, mientras para el rutilo puro las referencias reportadas en Meinhold (2010) de los números de onda son 612, 447, 247 y $143 \mathrm{~cm}^{-1}$. La variación en la intensidad relativa de los picos principales y secundarios podría estar relacionada a una mayor distorsión en las estructuras cristalinas y cambio del campo de ligandos en los sitios ocupados de los cristales, como lo explica la Teoría del campo de los ligantes (ej. Schläfer y Gliemann, 1969). En general, Raman es muy sensible a variaciones químicas y texturales. Las inclusiones de columbita medidas por su parte presentan números de onda en la banda Raman de 867 y $129 \mathrm{~cm}^{-1}$ y las de casiterita números de onda 731, 631, 492 y $121 \mathrm{~cm}^{-1}$, las cuales fueron comparadas con muestras de columbitatantalita provenientes de Venezuela en Franco (2015).

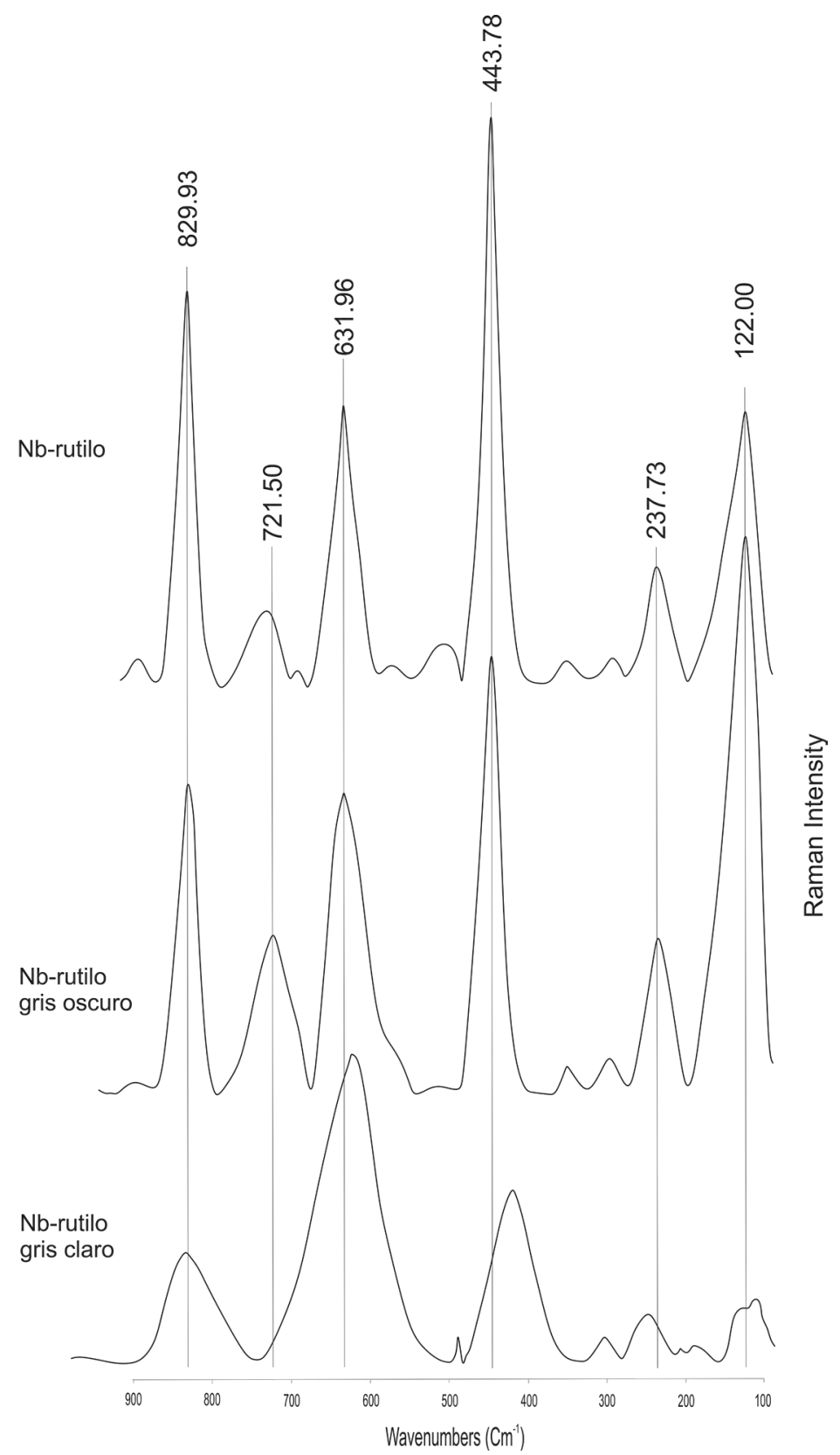

Figura 10. Espectrogramas Raman de rutilos-(Nb,Ta) de Cachicamo donde variaciones de tono y color en el mismo cristal de la muestra Col-17-C-I se reflejan en picos distintos. 
EPMA. Las imágenes composicionales de la microsonda de un rutilo-(Nb,Ta) (Figura 11) y su análisis cuantitativo (Quant1) confirmaron el Ti como componente principal, y Fe, $\mathrm{Nb}$ y Ta como elementos menores que forman parte de la estructura cristalina, pero además se encuentran enriquecidos en las inclusiones; en menor proporción elementos como $\mathrm{Pb}$ y W. El Mn y Sn están prácticamente restringidos a las inclusiones.
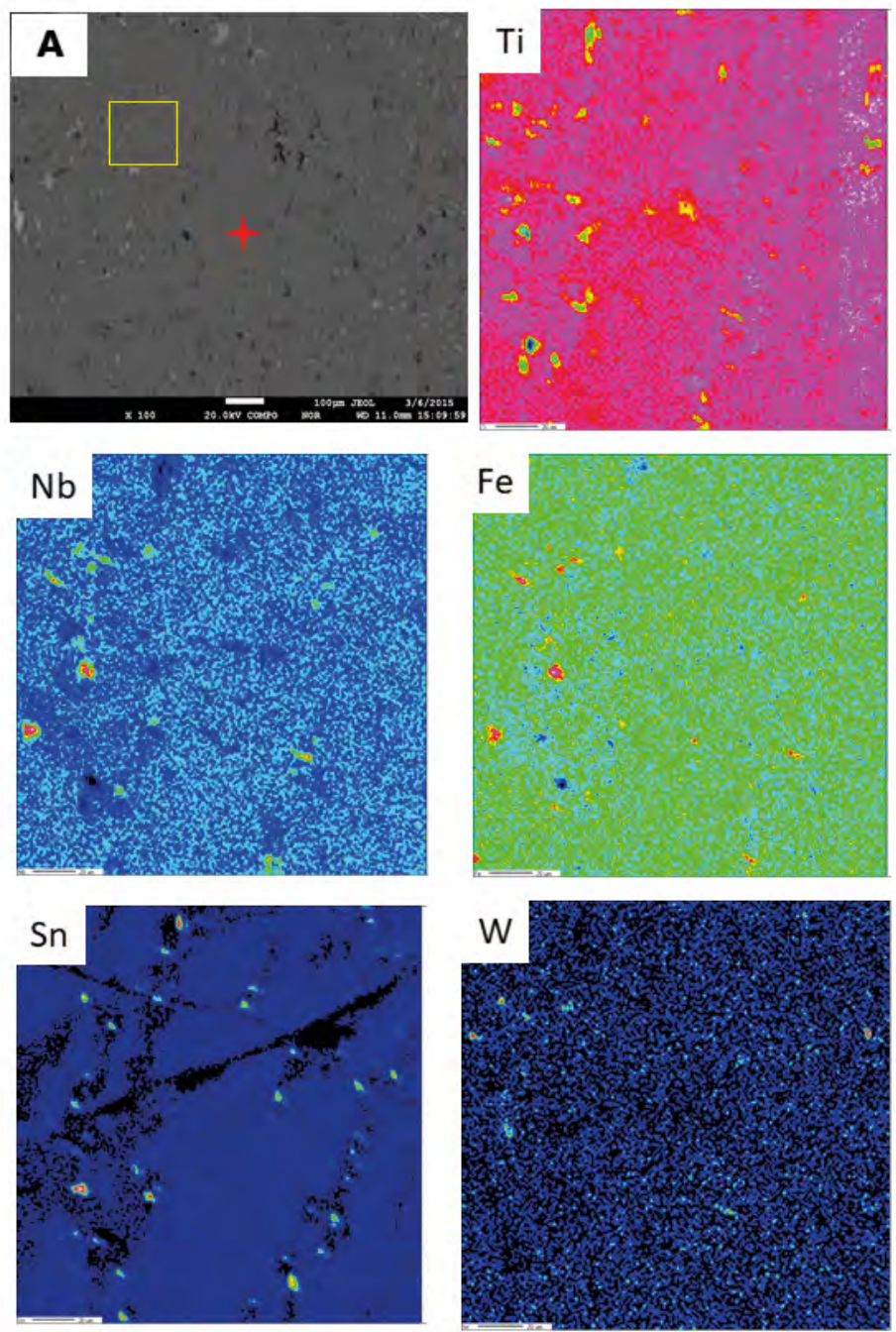
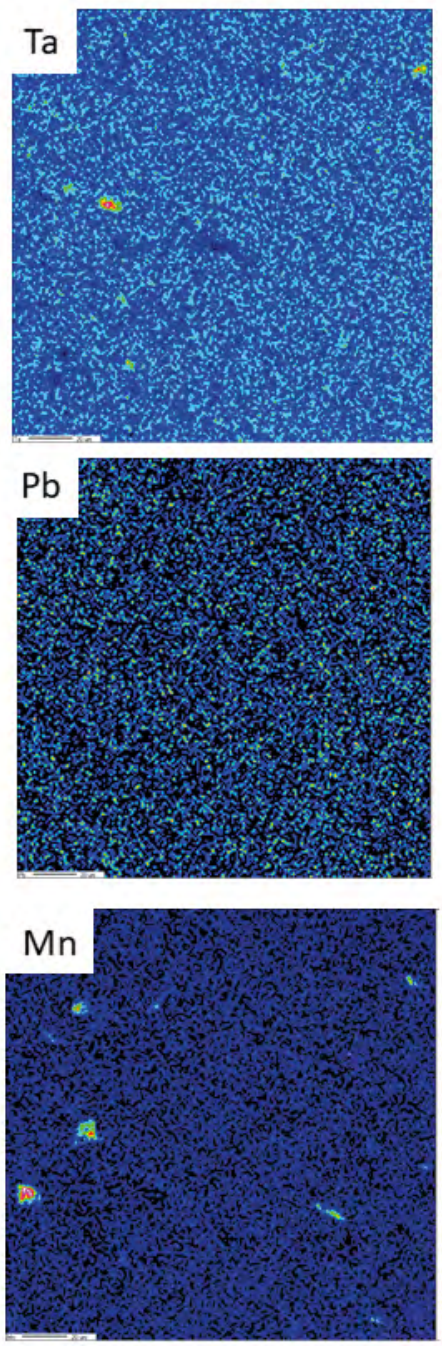

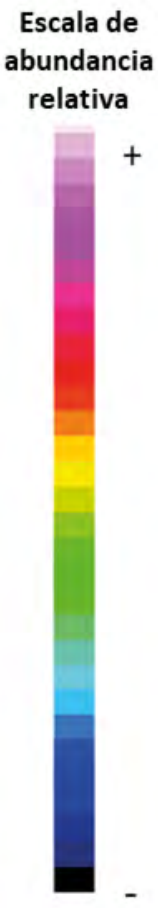

Figura 11. A. Imagen MEB mostrando la ubicación de los análisis. Las imágenes en color corresponden a los resultados del mapeo geoquímico con microsonda (rectángulo amarillo) para los elementos principales de un cristal de rutilo-( $\mathrm{Nb}$, Ta); nótese la heterogeneidad debido a las inclusiones de otros minerales. La estrella roja corresponde al lugar donde se realizaron los análisis cuantitativos presentados en este trabajo.

Para la fase mineral principal los resultados fueron graficados en un diagrama ternario $\mathrm{Ti}, \mathrm{Nb}, \mathrm{Ta}$ (Figura 12) que muestra una composición normalizada de Ti de $70 \%$ mientras que el $\mathrm{Nb}$ y $\mathrm{Ta}$ en un $15 \%$ para cada uno se encuentran en proporciones similares. Al comparar estos resultados con los anteriores de FRX (Figura 8) se observa una correlación positiva, aunque con valores mayores de Ti para los análisis puntuales y una relación en proporción muy similar en los contenidos de Nb y Ta. 


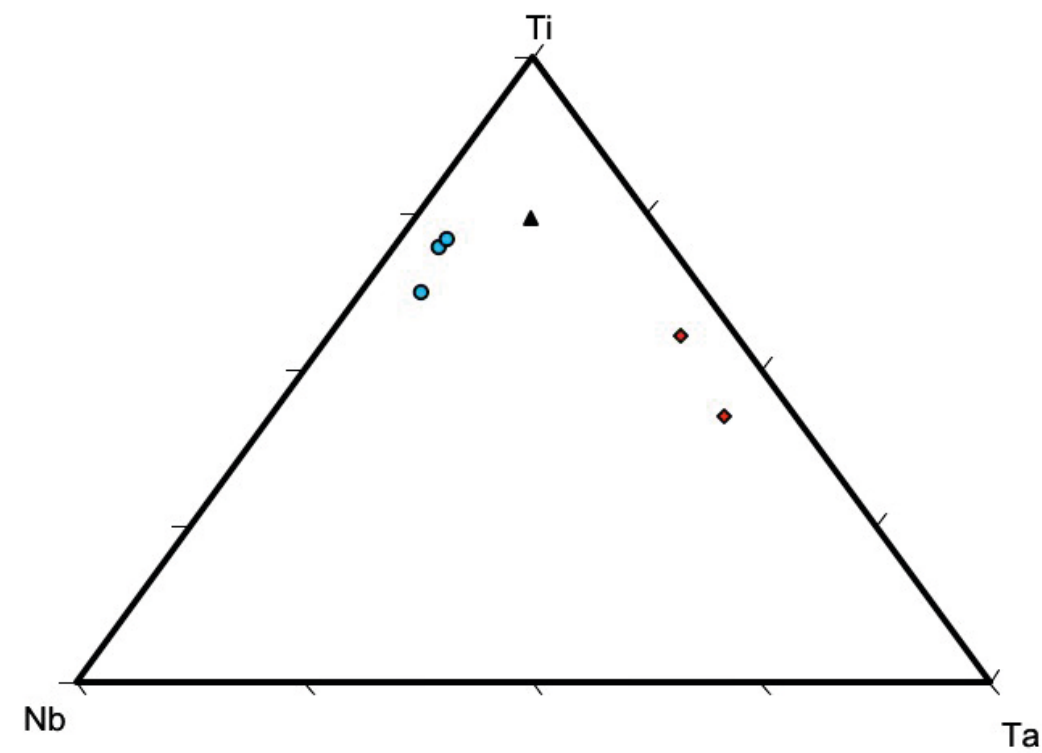

Figura 12. Diagrama ternario (Ti, Nb, Ta) de los rutilos según análisis cuantitativos de microsonda (EPMA). El triángulo representa los rutilos-(Nb,Ta) de Cachicamo, los círculos rutilos-(Nb) de pegmatitas de Canadá (Cerny et al., 1981) y los rombos rutilos-(Nb) de Venezuela (Aarden y Davidson, 1977).

Datación radiométrica $\mathrm{U}-\mathrm{Pb}$ en rutilos-(Nb,Ta) de Cachicamo. Los datos radiométricos $\mathrm{U} / \mathrm{Pb}$ (Tabla 3) de un total de 19 puntos de ablación fueron medidos en 10 fragmentos de cristales de rutilo-(Nb,Ta) (Figura
13), las correcciones y el diagrama concordia muestran una edad concordante de cristalización de $1512 \pm 12 \mathrm{Ma}$ con un parámetro MSWD=2.0 (Figura 14).
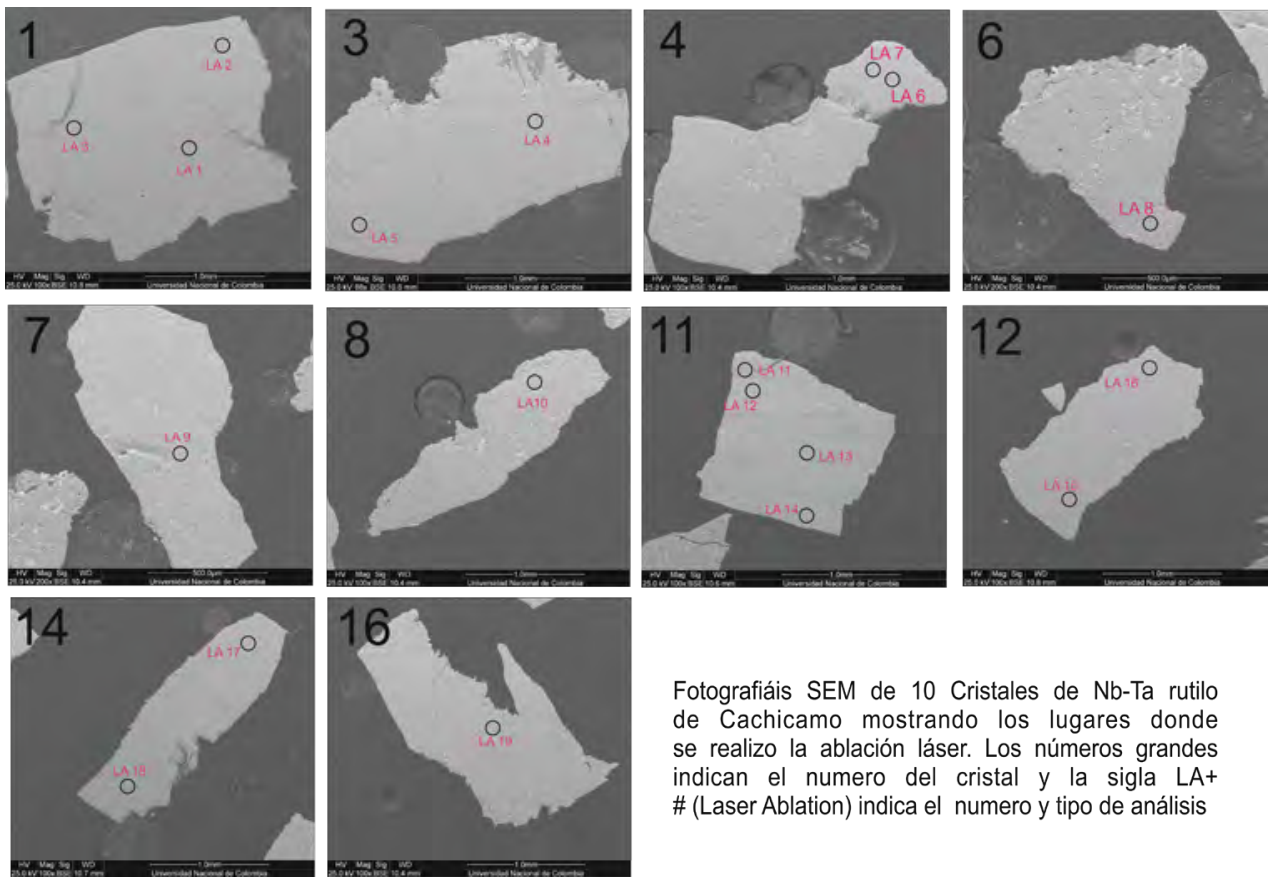

Fotografiáis SEM de 10 Cristales de $\mathrm{Nb}$-Ta rutilo de Cachicamo mostrando los lugares donde se realizo la ablación láser. Los números grandes indican el numero del cristal y la sigla LA+ \# (Laser Ablation) indica el numero y tipo de análisis

Figura 13. Fotografías MEB mostrando los 19 puntos de ablación láser en 10 cristales de rutilo-(Nb-Ta). 
Tabla 3. Relaciones isotópicas U/Pb obtenidas con LA-ICP-MS de 19 puntos en 10 cristales de rutilo-(Nb,Ta). Los datos en gris no se han representado en la Figura 14 ni se han utilizado para el cálculo de la edad, ya que contienen una cantidad alta de $\mathrm{Pb}$ común.

\begin{tabular}{|c|c|c|c|c|c|c|c|c|c|c|}
\hline \multirow{2}{*}{$\begin{array}{l}\text { Punto } \\
\text { de } \\
\text { Análisis }\end{array}$} & \multicolumn{4}{|c|}{ Radios isotópicos } & \multicolumn{6}{|c|}{ Edades aparentes } \\
\hline & ${ }^{238} \mathbf{U} /{ }^{206} \mathbf{P b}$ & $\begin{array}{c}\text { 2SigErr } \\
(\%)\end{array}$ & ${ }^{207} \mathbf{P b} /{ }^{206} \mathrm{~Pb}$ & $\begin{array}{c}\text { 2SigErr } \\
(\%)\end{array}$ & ${ }^{207} \mathrm{~Pb} /{ }^{235} \mathbf{U}$ & $\begin{array}{c}\text { 2SigErr } \\
\text { (Abs) }\end{array}$ & ${ }^{206} \mathrm{~Pb} /{ }^{238} \mathrm{U}$ & $\begin{array}{c}\text { 2SigErr } \\
\text { (Abs) }\end{array}$ & ${ }^{207} \mathbf{P b} /{ }^{206} \mathbf{P b}$ & $\begin{array}{c}\text { 2SigErr } \\
\text { (Abs) }\end{array}$ \\
\hline LA1 & 3,66 & 2,9 & 0,0891 & 2,3 & 1494 & 14 & 1557 & 19 & 1405 & 23 \\
\hline LA2 & 3,66 & 2,9 & 0,0910 & 2,3 & 1511 & 15 & 1557 & 19 & 1446 & 23 \\
\hline LA3 & 3,74 & 2,9 & 0,0931 & 2,3 & 1512 & 14 & 1528 & 19 & 1489 & 21 \\
\hline LA4 & 3,67 & 2,9 & 0,0968 & 2,3 & 1557 & 15 & 1553 & 19 & 1563 & 23 \\
\hline LA5 & 3,57 & 2,9 & 0,1147 & 2,3 & 1718 & 15 & 1592 & 20 & 1874 & 22 \\
\hline LA6 & 3,70 & 2,9 & 0,0980 & 2,4 & 1561 & 15 & 1542 & 19 & 1586 & 22 \\
\hline LA7 & 3,78 & 2,9 & 0,0929 & 2,2 & 1501 & 14 & 1513 & 19 & 1485 & 21 \\
\hline LA8 & 3,74 & 2,9 & 0,0934 & 2,2 & 1514 & 14 & 1528 & 19 & 1495 & 21 \\
\hline LA9 & 3,71 & 2,9 & 0,0926 & 2,2 & 1514 & 14 & 1539 & 19 & 1479 & 21 \\
\hline LA10 & 3,84 & 2,9 & 0,0951 & 2,2 & 1507 & 14 & 1492 & 19 & 1529 & 21 \\
\hline LA11 & 3,74 & 2,9 & 0,0931 & 2,2 & 1512 & 14 & 1528 & 19 & 1489 & 21 \\
\hline LA12 & 3,71 & 2,9 & 0,1091 & 2,1 & 1645 & 15 & 1539 & 19 & 1784 & 20 \\
\hline LA13 & 3,79 & 2,9 & 0,0934 & 2,2 & 1504 & 14 & 1510 & 19 & 1495 & 21 \\
\hline LA14 & 3,79 & 2,9 & 0,0919 & 2,1 & 1491 & 14 & 1510 & 19 & 1465 & 21 \\
\hline LA15 & 3,78 & 2,9 & 0,0938 & 2,2 & 1509 & 14 & 1513 & 19 & 1503 & 21 \\
\hline LA16 & 3,60 & 2,9 & 0,0938 & 2,2 & 1550 & 14 & 1584 & 20 & 1503 & 21 \\
\hline LA17 & 3,87 & 2,9 & 0,0942 & 2,4 & 1494 & 14 & 1482 & 19 & 1511 & 23 \\
\hline LA18 & 3,80 & 2,9 & 0,0923 & 2,3 & 1492 & 14 & 1506 & 19 & 1473 & 21 \\
\hline LA19 & 3,60 & 2,9 & 0,1188 & 2,1 & 1740 & 15 & 1580 & 20 & 1937 & 20 \\
\hline
\end{tabular}

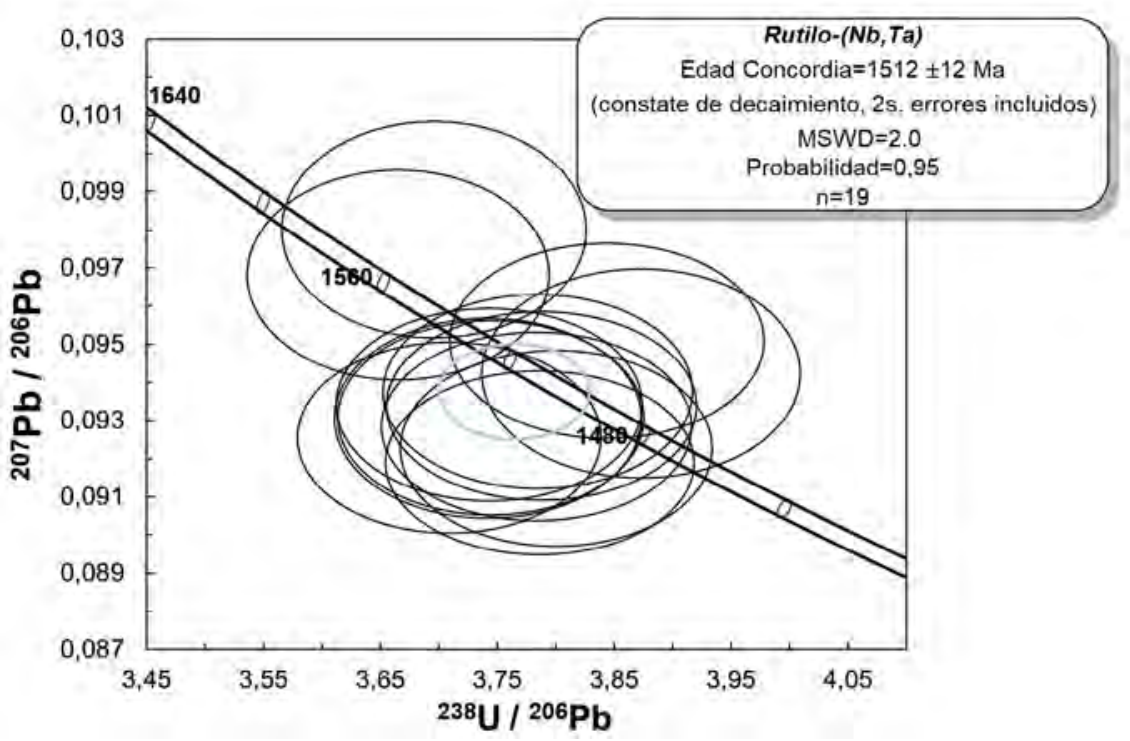

Figura 14. Diagrama de concordia obtenido de 19 mediciones (ver Tabla 3) realizadas en 10 cristales de rutilos-(Nb,Ta). 
Datación radiométrica $U-P b$ en circones de los horizontes A y C. Las edades de cristalización obtenidas en los circones detríticos analizados fueron graficadas en la curva de probabilidad relativa (Figura 15) para las edades concordantes exhibiendo dos rangos de edades así: circones del Horizonte C (regolito caolinizado) con edades entre 1400 y 1420 Ma y circones del Horizonte A (coraza ferruginosa), que contiene también los cristales de rutilo-(Nb,Ta), arrojan edades entre 1500-1550 Ma.

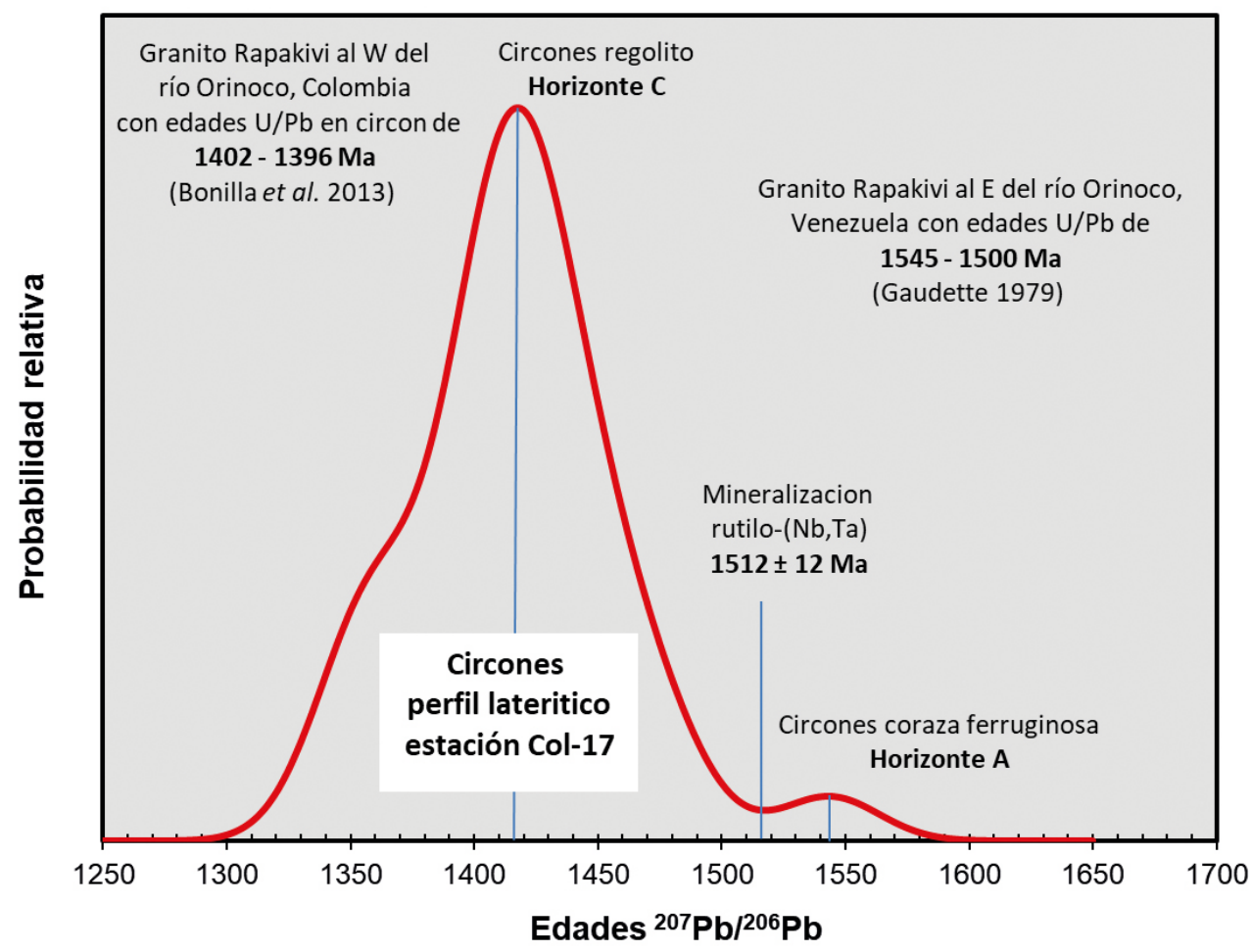

Figura 15. Gráfico de probabilidad relativa de edades para circones extraídos del perfil 1: Horizonte $\mathrm{C}$ (regolito) con edades de aproximadamente 1412 Ma y de circones del Horizonte A coraza ferruginosa con edades aproximadas a 1550 Ma. Adicionalmente datos de las edades de las rocas para la zona de estudio y la edad de la mineralización calculada en este trabajo.

\section{Discusión}

Mundialmente predomina un origen pegmatítico para mineralizaciones de rutilos-(Nb), casiteritas y columbitas-tantalitas (ej. Cerny et al., 1981; Mackay y Simandl, 2014). Las pegmatitas se forman en la última etapa de cristalización del magma y según Park y Macdiarmid (1981) representan una transición entre cuerpos graníticos intrusivos, filones y yacimientos minerales procedentes de fluidos hidrotermales, por lo cual deben tener edades similares o más jóvenes que el cuerpo intrusivo relacionado. En África, por ejemplo, pegmatitas más jóvenes que las identificadas en Colombia y Venezuela con edades $\mathrm{U} / \mathrm{Pb}$ de $968 \mathrm{Ma}$ (Dewaele et al., 2008) mineralizadas con columbita y casiterita en el área de Gatumba (Ruanda) están relacionadas a los llamados granitos de estaño de edad similar, afectados posteriormente por venas de cuarzo de 951 Ma. Emmons (1940) en Park y Macdiarmid (1981) reconoció que las pegmatitas con mayor valor comercial se presentan en las zonas superiores de los batolitos, dentro de las intrusiones o inyectadas en sus techos (ej. Simmons y Webber, 2008; London, 2008; Tkachev, 2011).

En cercanías a Puerto Carreño, en la zona El Burro - Aguamena, Estado de Bolívar, Venezuela, Aparicio et al. (1977) postulan que la fuente generadora de las manifestaciones de estos minerales fueron rocas pegmatíticas. La empresa Desarrollo Minero del Amazonas C.A. DEMINA concluyó que estas mineralizaciones (El Burro) se formaron en pegmatitas de cuarzo con $\mathrm{Ta}$, Nb, Sn, Zr, y Ti, como parte de las últimas etapas de cristalización de un magma ácido, lo cual proponen también Bolívar y Manrique (2011). En Colombia, estudios realizados en el Departamento del 
Vichada (ej. Galvis, 2001) confirmaron la presencia de una serie de diques pegmatíticos asociados en su mayoría al Granito de Parguaza (1400 Ma; BonillaPérez et al., 2013) como los observados principalmente en los cerros Bita, La Hormiga, Bandera, Santa Helena, Casuarito, San Roque, Guarípa, Cachicamo, Humeante y Palomazón en el municipio de Puerto Carreño (Figura 1 y 2), pero carentes de mineralización.

Las asociaciones mineralógicas y edades obtenidas en rutilo-(Nb,Ta) con inclusiones de casiterita y columbitatantalita sugieren un origen primario pegmatítico hace $1512 \pm 12 \mathrm{Ma}$, el mecanismo de emplazamiento típicamente corresponde a cúpulas de intrusiones graníticas en forma de bolsones mineralizados (Bettencourt et al., 2005). Sin embargo, en el área de estudio al occidente del río Orinoco no se han podido identificar diques pegmatíticos, ni venas de cuarzo que contengan la mineralización primaria, únicamente 150 $\mathrm{km}$ al sur de la zona de estudio, en cercanías de Puerto Nariño en la desembocadura del río Vichada al Orinoco, se encontraron depósitos coluviales con fragmentos de venas de cuarzo que contienen casiterita diseminada. Otros diques pegmatíticos que contienen minerales de Nb, Ta y Ti solamente han sido observados mucho más al sur, en San José - Departamento de Guainía (ver Figura 16).

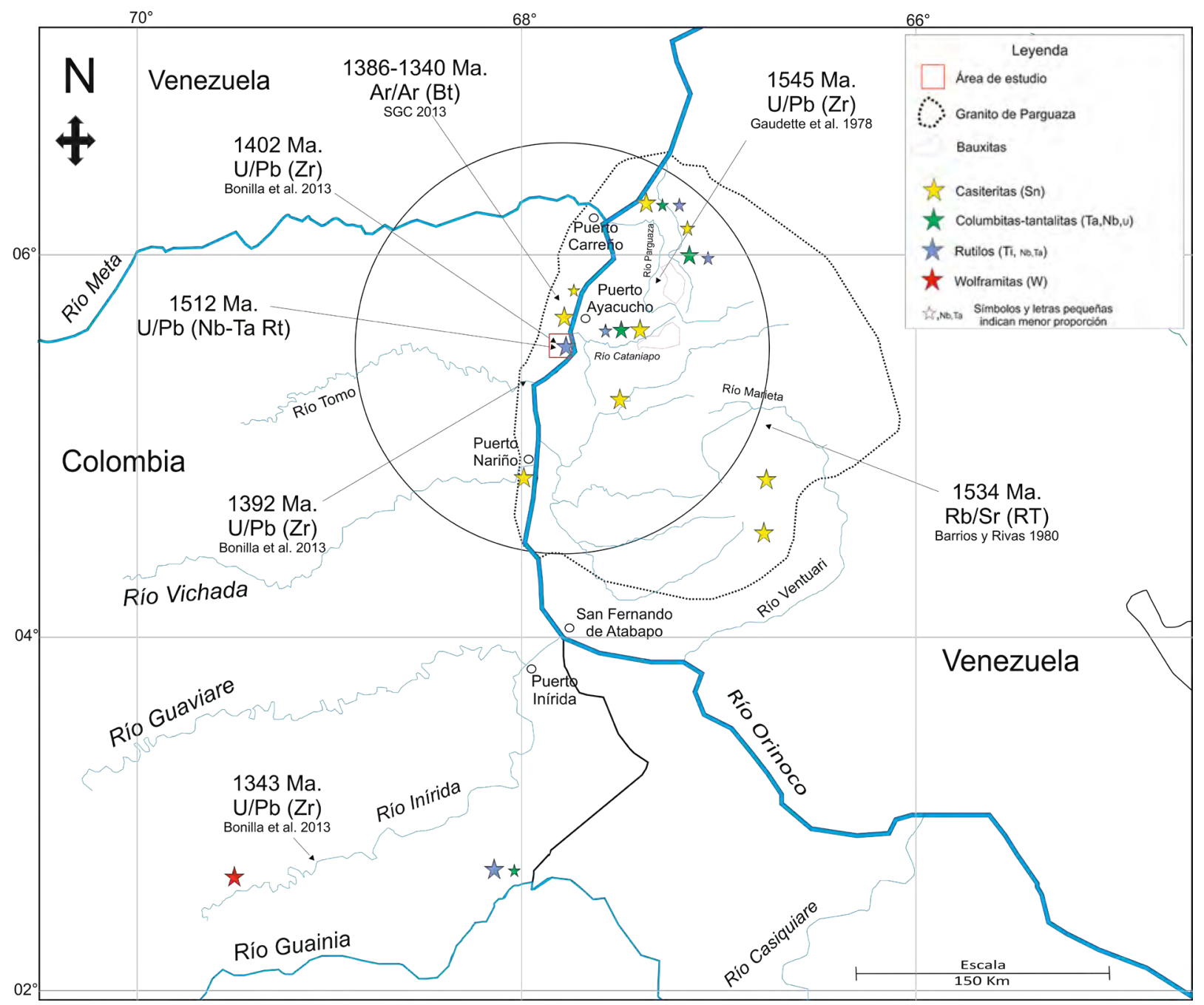

Figura 16. Mapa esquemático mostrando las edades reportadas por algunos autores para las rocas del Granito de Parguaza en Colombia y Venezuela. Las estrellas muestran los sitios donde se han reportado las diferentes ocurrencias en Venezuela y nuevas no reportadas en el territorio colombiano. Adicional se muestra la edad de los rutilos-(Nb,Ta). 
Los nuevos resultados sugieren que los rutilos ricos en Nb-Ta hallados en cercanías del Cerro Cachicamo fueron transportados desde su lugar de origen al actual yacimiento, pues edades $>1500$ Ma documentadas en cuerpos ricos en estas mineralizaciones solo se encuentran al E del Orinoco (Bolívar y Manrique, 2011; Mariño-Pardo, 2012, 2013). El transporte debió ser limitado y no influyó significativamente en su preservación dado su tamaño así como resistencia a la abrasión y meteorización química. Los perfiles estudiados en el depósito además contienen circones detríticos con edades entre 1400 y 1420 Ma concordantes con la edad de 1400 Ma para el Granito de Parguaza aflorante en los cerros dentro del territorio colombiano (ej. Cerros de Cachicamo y Humeante) y circones detríticos con edades entre 1500 y 1545 Ma que podrían corresponder al aporte también de los granitoides genéticamente relacionados a la mineralización.

Como área fuente pueden ser relacionadas las zonas cercanas en Venezuela, como Los Pijiguaos, Caño Aguamena, cerca de Puerto Ayacucho y en las localidades de El Burro y la Fortuna, donde han sido reportadas en diques pegmatíticos y venas de cuarzo mineralizaciones similares con casiteritas, columbitas, tantalitas, rutilos con niobio y tantalio, entre otros (comunicaciones personales y Mariño, 2012, 2013; Bolívar y Manrique, 2011). Aunque en estas mineralizaciones no han sido determinadas edades, se conoce que están emplazadas en rocas del Granito de Parguaza o posiblemente granitoides similares cuyas edades reportadas están entre 1500 y 1545 Ma de acuerdo con Gaudette et al. (1978).

La comparación de los rutilos-(Nb,Ta) de Cachicamo con minerales cristalográficamente similares y mineralógica-genéticamente correlacionados como las casiteritas de Cerro San Roque que muestran también maclas de Carlsbad y pequeñas inclusiones de estruverita y tantalita lo que refleja diferentes estados y cambios $(x, p H, E h, p, T)$ del fluido mineralizante sin y postmagmático. También cristales de estruverita, rutilo-(Nb) y columbita de depósitos coluvio-aluviales en las localidades de El Burro, La Fortuna y Aguamena ubicadas en cercanías a Puerto Ayacucho, Venezuela que fueron analizadas mediante FRX, SEM-EDS, DRX y Raman (Franco, 2015), confirman una fuerte afinidad geoquímica indicando un mismo origen.

\section{Conclusiones}

Los rutilos-(Nb,Ta) de Cachicamo hacen parte de un depósito secundario compuesto por fragmentos de corazas ferruginosas, pisolitos de óxidos e hidróxidos de $\mathrm{Fe}$, fragmentos de roca, cristales de cuarzo, feldespato y arenas con cuarzo, circón, magnetita e ilmenita incluidos paulatinamente en sincronía con los procesos de laterización conformando la coraza ferruginosa del horizonte superficial de un perfil laterítico desarrollado sobre rocas del Granito de Parguaza.

Se determinó una densidad promedio para 268 granos de rutilos-(Nb,Ta) de $4,83 \mathrm{~g} / \mathrm{cm}^{3}$ a diferencia de la densidad teórica $4,25 \mathrm{~g} / \mathrm{cm}^{3}$ para rutilos puros, evidencia de un enriquecimiento de $\mathrm{Nb}$ y Ta tanto en la estructura cristalina de este mineral (ilmenorutiloestruverita) como en forma de inclusiones con un aumento paralelo de la densidad hasta $5,9 \mathrm{~g} / \mathrm{cm}^{3}$.

Metalografía e imágenes SEM revelaron inclusiones de tamaños entre 10 a 250 micrómetros, de columbitatantalita y en menor media casiterita en una matriz de rutilo que contiene elementos como $\mathrm{Fe}, \mathrm{Nb}, \mathrm{Ta}$, $\mathrm{Mn}, \mathrm{Sn}$ y W indicando una relación genética con la cristalización de columbita-tantalita reportadas en territorio venezolano.

La comparación de las inclusiones de casiterita en los rutilos-(Nb,Ta) con casiteritas encontradas en Cerro San Roque indica un sistema o fluido mineralizante similar, así como una afinidad geoquímica con mineralizaciones de casiteritas y rutilos de El Burro y La Fortuna y columbitas y tantalitas de Aguamena en Venezuela, relacionadas al Granito de Parguaza.

Los contenidos de $\mathrm{U}$ y $\mathrm{Pb}$ en rutilos-(Nb, $\mathrm{Ta}$ ) eran suficientemente altos para permitir su datación radiométrica con LA-ICP-MS revelando edades de cristalización de 1512 \pm 12 Ma, concordante con las edades de cristalización de 1545-1500 Ma reportadas de las rocas del Granito de Parguaza u otros granitoides en Venezuela (Gaudette et al., 1978).

Las edades obtenidas de los circones del perfil laterítico del Horizonte C (regolito caolinizado) de 1415 Ma coinciden con las del Granito de Parguaza al oeste del río Orinoco en Colombia con edades de 1392 Ma y 1402 Ma, y el rango de edades más antiguas 
correspondientes a circones del horizonte A (coraza ferruginosa) coinciden con edades entre 1500 y 1545 Ma del Granito de Parguaza o granitoides asociados encontrados en Venezuela, por lo cual se demuestra que los rutilos provienen de estas últimas y que corresponden a la roca encajante de las mineralizaciones de rutilo-(Nb,Ta), casiterita y columbita-tantalita.

\section{Agradecimientos}

En especial a la Comunidad Indígena de Cachicamo por la colaboración en el acceso, reconocimiento y la recolección de muestras en el área de estudio. A los coinvestigadores del Grupo de Estudios en Geología Económica y Mineralogía Aplicada (GEGEMA). A Colciencias, al Servicio Geológico Colombiano (SGC) y al Fondo CTeI del Sistema General de Regalías por financiar los proyectos "Caracterización de mineralizaciones de niobio y tantalio en el oriente colombiano, su exploración, beneficio y posibles usos" e "Investigación de minerales estratégicos, industriales y materiales de construcción, Región Llanos". No por último a María Alexandrovna Sitnikova, Torsten Graupner y Frank Melcher de la BGR Hannover y a Heinrich Adolf Horn (UFMG) por soportar con análisis MEB, MLA y EPMA. Mauricio Ibáñez y un revisor anónimo ayudaron en mejorar el manuscrito.

\section{Referencias}

Aarden, H.M.; Davidson. M.T. (1977). Minerales de estaño, niobio, tántalo y titanio en la zona del Cano Aguamena, Estado Bolívar, analizados con microsonda de electrones. V Congreso Geológico Venezolano, Caracas, Venezuela.

Aparicio, O.J.; González, E.; Rivera L.R. (1977). Estudio geoeconómico preliminar para prospección de minerales de estaño en el área de Aguamena, Territorio Federal, Amazonas, Venezuela. V Congreso Geológico Venezolano, Caracas, Venezuela.

Barrios, F.; Rivas, D. (1980). Reconocimiento geocronológico del Territorio Federal Amazonas, Venezuela. Boletín de la Sociedad Venezolana de Geólogos, 21, 1-12.

Bettencourt, J.S.; Tosdal, R.M.; Leite, W.B.; Payolla, B.L. (1999). Mesoproterozoic rapakivi granites of the Rondônia Tin Province, southwestern border of the Amazonian craton, Brazil - I.
Reconnaissance U-Pb geochronology and regional implications. Precambrian Research, 95(1-2), 41-67. https://doi.org/10.1016/S03019268(98)00126-0

Bettencourt, J.S.; Leite, W.B.; Goraieb, C.L.; Sparrenberger, I.; Bello, R.; Payolla, B.L. (2005). Sn-polymetallic greisen-type deposits associated with late-stage rapakivi granites, Brazil: fluid inclusion and stable isotope characteristics. Lithos, 80(1-4), 363-386. https://doi.org/10.1016/j. lithos.2004.03.060

Best, M.G. (2003). Igneous and metamorphic petrology. (2nd ed) Blackwell publishing.

Bolívar, P.A.; Manrique, A.C. (2011). Estudio preliminar de los depósitos de tantalita, columbita y casiterita, a través de imágenes spot de la hoja 6734 de cartosur i y ii, en la zona suroeste del Municipio Cedeño, Estado Bolívar, Venezuela. Tesis, Universidad de Oriente, Ciudad Bolívar.

Bonilla-Pérez, A.; Frantz, J.C.; Charão-Marques, J.; Cramer, T.; Franco, J.A.; Mulocher, E.; AmayaPerea, Z. (2013). Petrografía, geoquímica y geocronología del Granito de Parguaza en Colombia. Boletín de Geología, 35(2), 83-104.

Bonilla, A.; Frantz, J.C.; Charão-Marques, J.; Cramer, T.; Franco, J.A.; Amaya, Z. (2016). Magmatismo rapakivi en la cuenca del rio Inirida, departamento de Guainía, Colombia. Boletín de Geología, 38(1), 17-32. https://doi.org/10.18273/revbol. v38n1-2016001

Bonilla, A.; Cramer, T.; Poujol, M.; Cano, H.; Franco, J.A.; Amaya, Z. (2019). Petrografía, geoquímica y geocronología $\mathrm{U} / \mathrm{Pb}$ en circones de rocas ígneas y metamórficas a lo largo del río Cuiarí en el sur del Departamento de Guainía, Colombia. Boletín de Geología, 41(1), 55-84. https://doi.org/10.18273/ revbol.v41n1-2019003

Boutin, A.; De Saint Blanquat, M.; Poujol, M.; Boulvais, P.; De Parseval, P.; Rouleau.; Robert, J.F. (2016). Succession of Permian and Mesozoic metasomatic events in the eastern Pyrenees with emphasis on the Trimouns talc-chlorite deposit. International Journal of Earth Sciences, 105(3), 747-770. https://doi.org/10.1007/s00531-0151223-x 
Bracciali, L.; Parrish, R.R.; Horstwood, M.S.A.; Condon, D.J.; Najman, Y. (2013). U-Pb LA-(MC)ICP-MS dating of rutile: New reference materials and applications to sedimentary provenance. Chemical Geology, 347, 82-101. https://doi. org/10.1016/j.chemgeo.2013.03.013

Brooks, W.E.; Gray, F. (1993). Tin-(rare earth element, niobium-tantalum) placers. In: Geology and mineral resources assessment of the Venezuelan Guayana Shield (p. 88-89). Vol. 2062. Geological Survey and Corporación Venezolana de Guayana, Técnica Minera C.A.

Büdel, J. (1981). Klima-Geomorphologie. Gebrüder Borntraeger.

Buenaventura, J.; Rosas, H. (1988). Reconocimiento geológico-minero entre la región de Puerto Carreño y Puerto Nariño, Comisaría del Vichada. INGEOMINAS, Bogotá.

Carlson, R.W. (2011). Absolute age determinations: Radiometric. In: H.K. Gupta (eds.). Encyclopedia of Solid Earth Geophysics (pp. 1-8). Springer Netherlands. https://doi.org/10.1007/978-90-4818702-7_69

Carrasco, E.; Peña, L.G. (2006). Determinación de zonas óptimas para exploración en el Oriente Colombiano a través de modelamiento geoquímico. INGEOMINAS, Bogotá, Colombia.

Cerny, P.; Pault, B.J.; Hawthorne, F.C.; Chapman, R. (1981). A niobian rutile - disordered columbite intergrowth from The Huron claim pegmatite, southeastern Manitoba. Canadian Mineralogist, 19, 541-548.

Cordani, U.G.; Sato, K.; Sproessner, W.; Fernandes, F.S. (2016). U-Pb zircon ages of rocks from the Amazonas Territory of Colombia and their bearing on the tectonic history of the NW sector of the Amazonian Craton. Brazilian Journal of Geology, 46(Suppl. 1), 5-35. https://doi.org/10.1590/23174889201620150012

Cramer, T.; Franco, J.A.; Bonilla, A.; Poveda, A.; Amaya, Z. (2011). Caracterización de depósitos aluviales con manifestaciones de Tantalio y Niobio (Coltán) en las comunidades indígenas de Matraca y Caranacoa en el Departamento del Guainía. INGEOMINAS, Bogotá, Colombia.
Cristancho, J.I. (1989). Posibilidades de mineralizaciones de importancia económica en el Granito de Parguaza, en alrededores de Puerto Carreño (Vichada - Colombia). Tesis, Universidad Nacional de Colombia, Bogotá, Colombia.

Dall'Agnol, R.; Costi, H.; Leite, A.A.; de Magalhañes, M.; Teixeira, N. (1999). Rapakivi granites from Brazil and adjacent areas. Precambrian Research, 95(1-2), 9-39. https://doi.org/10.1016/S03019268(98)00125-9

Dewaele, S.; Tack, L.; Fernandez, M.; Boyce, A.; Muchez, P.; Schneider, J.; Cooper, G.; Wheeler, K. (2008). Geology and mineralization of the Gatumba area, Rwanda: Present stage knowledge. Etudes Rwandaises, 16, (6-23).

Dill, H.G.; Melcher, F.; Füßl, M.; Weber, B. (2006). Accessory minerals in cassiterite: A tool for provenance and environmental analyses of colluvial-fluvial placer deposits (NE Bavaria, Germany). Sedimentary Geology, 191(3-4), 171-189. https://doi.org/10.1016/j. sedgeo.2006.03.022

Emmons, W.H. (1940). Principles of economic geology. The Journal of Geology, 48(4), 446-447. https://doi.org/10.1086/624902

Franco, J.A. (2011). Asociaciones minerales de depósitos aluviales relacionados a cuerpos ígneometamórficos aflorantes en las Comunidades Indígenas de Matraca y Caranacoa, río Inírida, Departamento del Guainía. Trabajo de grado, Universidad Nacional de Colombia, Bogotá, Colombia.

Franco, J.A. (2015). Contribución a la geología histórica del Oriente Colombiano: Proveniencia de minerales metálicos con Nb, Ta, Mn, Fe, Ti, Sn y W, de un depósito laterizado, en cercanías a la Comunidad Indígena de Cachicamo, al NE del Departamento del Vichada. Tesis de Maestría, Universidad Nacional de Colombia, Bogotá, Colombia.

Galvis, J. (2001). Aspectos geológicos del nordeste del departamento del Vichada: Colombia. INGEOMINAS, Bogotá, Colombia.

Gaudette, H.E.; Mendoza, V.; Hurley, P.M.; Fairbairn, H.W. (1978). Geology and age of the Parguaza 
rapakivi granite, Venezuela. GSA Bulletin, 89(9), 1335-1340. https://doi.org/10.1130/00167606(1978)89<1335:GAAOTP>2.0.CO;2

Hanaor, D.A.H.; Sorrell, C.C. (2011). Review of the anatase to rutile phase transformation. Journal of Materials Science, 46(4), 855-874. https://doi. org/10.1007/s10853-010-5113-0

Howard, K.E.; Hand, M.; Barovich, K.M.; Reid, A.; Wade, B.P.; Belousova, E.A. (2009). Detrital zircon ages: improving interpretation via $\mathrm{Nd}$ and Hf isotopic data. Chemical Geology, 262(3-4), 277-292. https://doi.org/10.1016/j. chemgeo.2009.01.029

INGEOMINAS-USGS. (1986). Mapa de terrenos geológicos de Colombia. Publicaciones Geológicas Especiales del Ingeominas, 14, 1-235.

INGEOMINAS. (2006). Potencial de recursos minerales en el oriente colombiano: compilación y análisis de la información geológica disponible. Bogotá.

INGEOMINAS. (2009). Memoria explicativa de las planchas 162, 162 bis, 182 y 182 bis Puerto Carreño, Vichada. Bogotá.

Jackson, S.E.; Pearson, N.J.; Griffin, W.L.; Belousova, E.A. (2004). The application of laser ablationinductively coupled plasma-mass spectrometry to in situ U-Pb zircon geochronology. Chemical Geology, 211(1-2), 47-69. https://doi. org/10.1016/j.chemgeo.2004.06.017

Košler, J.; Sylvester, P.J. (2003). Present trends and the future of zircon in geochronology: laser ablation ICPMS. Reviews in Mineralogy and Geochemistry, 53(1), 243-275. https://doi.org/10.2113/0530243

London, D. (2008). Pegmatites. Vol. 10. Mineralogical Association of Canada.

López-Africano, P.E. (1998). Minería - Guainía aspectos geológicos, mineros $\mathrm{y}$ ambientales cuenca media y alta de los ríos Guainía e Inírida: Puerto Inírida, Convenio Andrés Bello - Secab. Contrato Sena - Secab - Nro. 0051-97. INGEOMINAS, Bogotá.

López, J.A.; Khurama, S.; Bernal, L.E.; Cuéllar, M.A. (2007). El complejo Mitú: una nueva perspectiva. XI Congreso Colombiano de Geología, Bucaramanga, Colombia. https://doi. org/10.13140/2.1.3164.0968

López, J.; Mora, B.; Jiménez, D.M.; Khurama, S.; Marín, E.; Obando, G.; Páez, T.I.; Carrillo, L.E.; Bernal, L. (2010). Cartografía geológica y muestreo geoquímico de las Planchas 297-Puerto Inírida, 297 Bis - Merey Y 277 Bis - Amanaven, Departamento del Guainía. INGEOMINAS, Bogotá.

Ludwig, K.R. (2012). User's manual for Isoplot 3.75 - A Geochronological Toolkit for Microsoft Excel, Berkeley Geochronology Center Special Publication. No. 5. pp. 1-72.

Mackay, D.A.R.; Simandl, G.J. (2014). Geology, market and supply chain of niobium and tantalum - a review. Mineralium Deposita, 49(8), 1025-1047. https://doi.org/10.1007/s00126-0140551-2

Manzotti, P.; Poujol, M.; Ballèvre, M. (2015). Detrital zircon geochronology in blueschist-facies meta-conglomerates from the Western Alps: implications for the late Carboniferous to early Permian paleogeography. International Journal of Earth Sciences, 104(3), 703-731. https://doi. org/10.1007/s00531-014-1104-8

Mariño-Pardo, N. (2012). Potencial minero del Bajo Parguaza. Revista Commodities Venezolanos, 2(6), 44-47.

Mariño-Pardo, N. (2013). Coltán (Nb y Ta): Ubicación, extracción ilegal y potencial minero, en el municipio Cedeño del Estado Bolívar. Venezuela: Propuestas. V Simposio Venezolano de Geociencias de Rocas Ígneas y Metamórficas. Caracas, Venezuela.

Meinhold, G. (2010). Rutile and its applications in earth sciences. Earth-Science Reviews, 102(1-2), 1-28. https://doi.org/10.1016/j.earscirev.2010.06.001

Melcher, F.; Graupner, T.; Gäbler, H.E.; Sitnikova, M.; Henjes-Kunst, F.; Oberthür, T.; Gerdes, A.; Dewaele, S. (2015). Tantalum-(niobiumtin) mineralisation in African pegmatites and rare metal granites: Constraints from $\mathrm{Ta}-$ $\mathrm{Nb}$ oxide mineralogy, geochemistry and U$\mathrm{Pb}$ geochronology. Ore Geology Reviews, 
64, 667-719. https://doi.org/10.1016/j. oregeorev.2013.09.003

Melcher, F.; Graupner, T.; Gäbler, H.E.; Sitnikova, M.; Oberthür, T.; Gerdes, A.; Badanina, E.; Chudy, T. (2017). Mineralogical and chemical evolution of tantalum-(niobium-tin) mineralisation in pegmatites and granites. Part 2: Worldwide examples (excluding Africa) and an overview of global metallogenetic patterns. Ore Geology Reviews, 89, 946-987. https://doi.org/10.1016/j. oregeorev.2016.03.014

Mendoza, V. (2012). Geología de Venezuela. Gran Colombia Gold Corp.

Nasdala, L.; Beyssac, O.; Schopf, J.W.; Bleisteiner, B. (2012). Application of Raman-based Images in the Earth Sciences. In: A. Zoubir (ed.). Raman Imaging (pp. 145-187). Vol. 168. Springer Berlin Heidelberg. https://doi.org/10.1007/978-3-64228252-2_5

Navas, O. (1991). Informe geológico sector Puerto Carreño - Casuario, margen occidental del río Orinoco-Comisaria del Vichada. INGEOMINAS, Bogotá, Colombia.

Park, C.; Macdiarmid, R. (1981). Yacimientos minerales. Omega.

Priem, H.; Andriessen, P.; Boelrijk, N.; De Boorder, H.; Hebeda, E.; Huguett, A.; Verdumen, E.; Verschure, R. (1982). Geochronology of the Precambrian in the Amazonas region of Southeastern Colombia (Western Guainía Shield). Geologie Minjnbouw, 61(3), 229-242.

Rodríguez, S.E. (1996). Posibilidades de ubicar depósitos residuales de tantalita asociados con el Batolito de Parguaza. Región Oriental del Departamento del Vichada. INGEOMINAS, Bogotá.

Santos, J.O.S.; Hartmann, L.A.; Gaudette, H.E.; Groves, D.I.; Mcnaughton, N.J.; Fletcher, I.R. (2000). A new understanding of the Provinces of the Amazon Craton based on Integration of Field Mapping and $\mathrm{U}-\mathrm{Pb}$ and $\mathrm{Sm}-\mathrm{Nd}$ Geochronology. Gondwana Research, 3(4), 453-488. https://doi. org/10.1016/S1342-937X(05)70755-3
Servicio Geológico Colombiano (2013). Cartografía geológica y muestreo geoquímico de las planchas 201 BIS, 201, 200 y 199 Departamento de Vichada. Memoria explicativa. 160 p.

Schläfer, H.L.; Gliemann, G. (1969). Basic Principles of Ligand Field Theory. Wiley Interscience.

Sial, A.N.; Bettencourt, J.S.; De Campos, C.P.; Ferreira, V.P. (2011). Granite-related ore deposits: an introduction. Geological Society, London, Special Publications, 350, 1-5. https://doi.org/10.1144/ SP350.1

Sidder, G.B.; Mendoza, V. (1995). Geology of the Venezuela Guayana Shield and its relation to the Geology of the entire Guayana Shield. U.S. Geological Survey, Bull No. 2124, pp. B1-B41. https://doi.org/10.3133/ofr91141

Simmons, W.B.; Webber, K.L. (2008). Pegmatite genesis: state of the art. European Journal of Mineralogy, 20(4), 421-438. https://doi. org/10.1127/0935-1221/2008/0020-1833

Sláma, J.; Košler, J.; Condon, D.J.; Crowley, J.L.; Gerdes, A.; Hanchar, J.M.; Horstwood, M.S.A.; Morris, G.A.; Nasdala. L.; Norberg, N.; Schaltegger, U., Schoene, B.; Tubrett, M.N.; Whitehouse, M.J. (2008). Plešovice zircon - A new natural reference material for $\mathrm{U}-\mathrm{Pb}$ and Hf isotopic microanalysis. Chemical Geology, 249(1-2), 1-35. https://doi.org/10.1016/j. chemgeo.2007.11.005

Sylvester, P. (2012). Quantitative mineralogy and microanalysis of sediments and sedimentary rocks. Mineralogical Association of Canada Short Course Volume 42.

Tassinari, C.C.G.; Macambira, M.J.B. (1999). Geochronological provinces of the Amazonian Craton. Episodes, 22(3), 174-182. https://doi. org/10.18814/epiiugs/1999/v22i3/004

Tkachev, A.V. (2011). Evolution of metallogeny of granitic pegmatites associated with orogens throughout geological time. Geological Society, London, Special Publications, 350(1), 7-23. https://doi.org/10.1144/SP350.2 
Watson, E.B.; Wark, D.A.; Thomas, J.B. (2006). Crystallization thermometers for zircon and rutile. Contributions to Mineralogy and Petrology, 151(4), 413-433. https://doi.org/10.1007/s00410006-0068-5

Zack, T.; Von Eynatten, H.; Kronz, A. (2004). Rutile geochemistry and its potential use in quantitative provenance studies. Sedimentary Geology, 171(1-4), 37-58. https://doi.org/10.1016/j. sedgeo.2004.05.009
Zack, T.; Stockli, D.F.; Luvizotto, G.L.; Barth, M.G.; Belousova, E.; Wolfe, M.R.; Hinton, R.W. (2011). In situ U-Pb rutile dating by LA-ICPMS: ${ }^{208} \mathrm{~Pb}$ correction and prospects for geological applications. Contributions to Mineralogy and Petrology, 62(3), 515-530. https://doi. org/10.1007/s00410-011-0609-4

Fecha de recibido: 26 de mayo de 2020 Fecha de aprobado: 09 de noviembre de 2020 